\title{
La cultura Tiahuanaco vista a la luz de la arqueología contemporánea
}

por

liederico Kaufimann Doig

Este bosquejo está dedicado a mis alumnos universitarios del curso de "Arqueología Peruana". No es otra cosa que un resumen apresurado de mis apuntes de clase, del capítulo correspondiente a la cultura Tiahuanaco. Está escrito sin pretenciones eruditas, con sólo el objeto de ofrecer al estudiante un derrotero del que carecía, sintético y redactado de modo sencillo. Las referencias bibliográficas le permitirán ahondar en los distintos aspectos y problemas que plantea la arqueología Tiahuanaco (Huari)

El concepto sobre la antiguedad de la cultura Tiahuanaco que rige hoy, es muy "distinto afque imperabar" $\mathrm{e}$ "el siglo $X I X, y$ al sostenido por A. Posnansky, aisladamente, hasta todavia uno o dos decenios. Desde el siglo XVI, en que destaca la descripción de las ruinas de Tiahuanaco hecha por Cieza de León, este centro arqueológico vino a representar la "cultura preincaica" por antonomasia. El gran cultor de su arqueologia, Posnansky, llegó a estimar hasta en 14,000 años su antigüedad. Con las investigaciones del sabio Max Uhle, la posición cronológica de Tiahuanaco quedó establecida en la medida que hoy se acepta. Pero más importante es que Uhle logró definir la posición que corresponde a Tiahuanaco frente a las demás culturas que tuvieron por escenario el antiguo Perú. Uhle descubrió que la difusión de la cultura Tiahuanacoide se presentaba sólo después de Nasca y de Mochica: Es una cultura que en determinado momento, hacia el siglo $1 X$ ó $X$

El personaje central de la "Portada del Sol" de Tiahuanaco. 
D.C., desourcla por todo el territorio peruano sobreponiendose a las uistintás culiuras locales. Es pues impcrtante diferenciar, teóricamente, una epoca de gestación y desarrollo local y otra de expansión. Queda en discusion hasta la iecha de si las ruinas de Tiahuanaco en el riticaca fueron o no el asiento originario de la cultura liainuanaco, aunque Bennett y ahora Ponce Sangines en sus excavaciones, han coriseguido hallar alguna documentación sobre formas pre-7iahuanéco en la región que ocupan las ruinas. Lo que ha variado sustanciairnente, en los últimos años, es el concepto acerca del punto de difusión de la cultura "Tiahuanaco". Se estima hoy que la influencia Tiahuanaco que recibió la costa y la sierra, de norte a sur, no partio directamente de las ruinas de Tiahuanaco. Las zonas arqueológicas cie Huari, en Ayacucho, y luego la de Pachacamac, en la Costa Central, habrían sido los importantes centro de dispersión Tiahuanaco. El estilo Tiahuanaco llegado por importación a estos dos sitios, acampa y se mezcla con elementos locales antes de irradiar nuevamente, hasta influir en toda la costa y sierra peruanas, y talvez más allá de las fronteras actuales de nuestro país. Con todo, queda un hecho hasta hoy incuestionable, y es que en el Tiahuanaco, del Titicaca, se da con profusión clásica el estilo que caracteriza la cultura que nos ocupa. Los comienzos de la expansión del estilo Tiahuanaco tienen lugar. según las apreciaciones últimas, hacia 800 ó 900 D.C. Se da por terminada estå etapa, hacia 1,200 D.C. cuando el estilo Tiahuanaco se simplifica y es desplazado por nuevos estilos locales, que, naturalmente, cónservan algunas supervivencias tiahuanacotas, pero con elementos secundarios frente a los nuevos dominantes, que a su vez se inspiran en cánones pretiahuanaquenses de la tradición local o regional, según las diferentes subáreas.

La difusión amplia del estilo Tiahuanaco, que es pan-peruano como el de los Incas, ha motivado que se le considere un horizonte. La escuela de Calfiornia lo nombra Horizonte Medio, porque se encuentra en una posición central en el tiempo, con respecto al estilo Chavín (Horizonte Temprano) y al Inca (Horizonte Tardio). Por otra parte, los arqueólogos prefieren llamar al estilo Tiahuanaco que se da fuera del yacimiento de ese nombre tiahuanacoide, porque este término indica "parecido a". Y en verdad, la difusión amplia del estilo Tiahuanaco, le impregna variedades debidas a la

Tela tiahuanacoide, hallada en la Costa (Museo Etnográfico do Munich). $\longrightarrow$ 



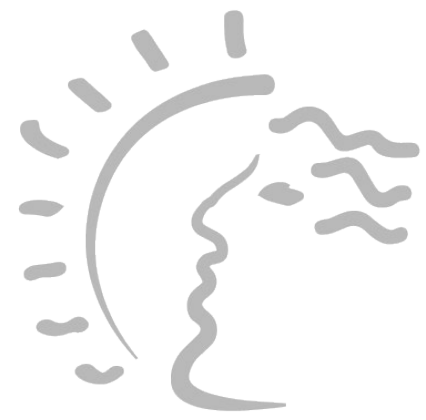

Biblioteca de Letras "Jorge Puccinelli Converso" 
adaritación en zonas apartadas, y a las naturales transformaciones que sufre un estilo en el tiempo. También esta etapa ha recibido el nombre cle período de Fusión, pero hay que advertir que éste se presta - inexactas interpretaciones, pues no se da exactamente con Tiahuanaco un crisol donde se funden todos los estilos anteriores. Tiahuanaco actúa en forma de superposición, recibiendo en alguros casos mezclas regionales, que a su vez suele transmitir a otras zonas, pero no funde, o fusiona, los estilos locales entre si. En este comentario mantendremos el término tradicional, con las aclaraciones anteriormente expuestas, y tomancio en consideración que el sitio clásico sigue estimándose ser el sitio Tiahuanaco, en el Lago Titicaca. $Y$ es en efecto aquí donde se encuentran raíces del estilo que más tarde sufre cambios ambientales y de propia evolución; de ahí que demos por entendido que Tiahuanaco en su expansión sea naturalmente "tiahuanacoide". Pero, antes de revisar el proceso de la difusión de los elementos tiahuanaquenses veamos, brevemente, el estilo Tiahuanaco a través de los exponentes que aún quedan de esta cultura a orillas del lago Titicaca.

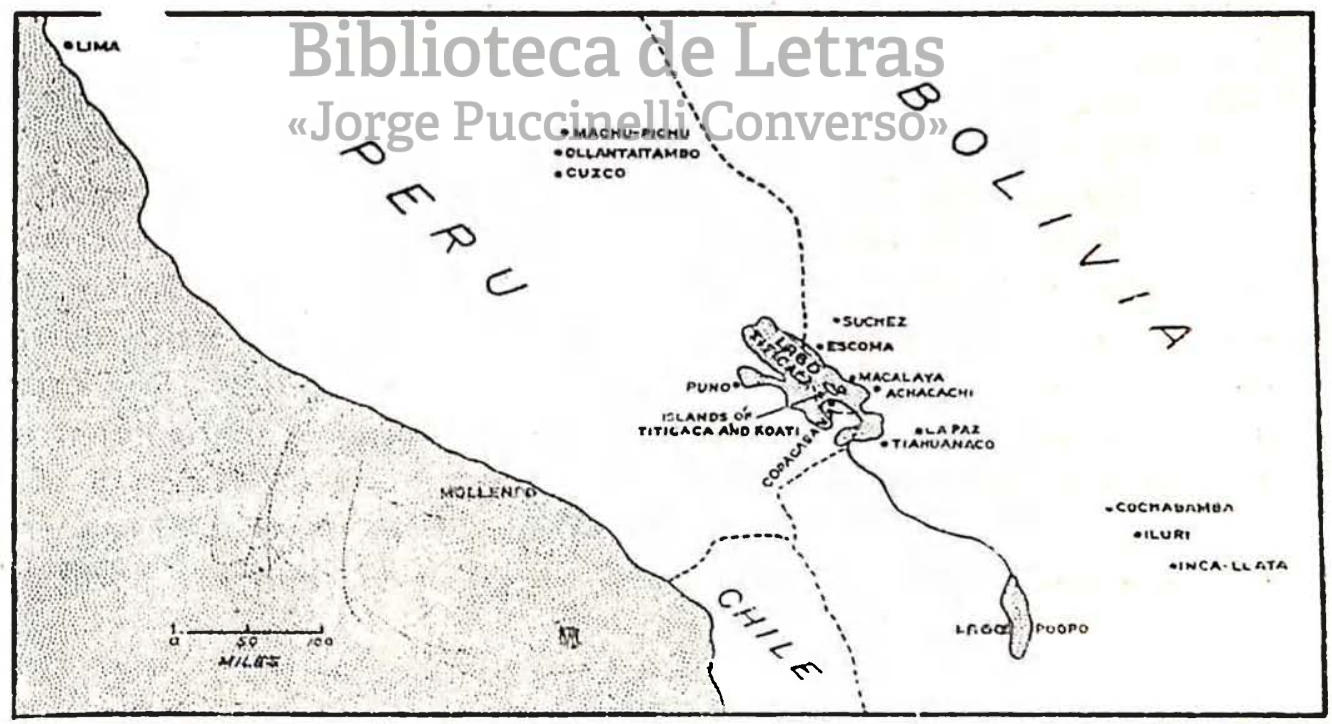




\section{TIAHUANACO DEL TITICACA}

\section{1.-Las ruinas del Tiahuanaco.}

La primera referencia a los monumentos pétreos de Tiahuanaco es la de Pedro Cieza de León, quien visitó el lugar entre 1540 y 1550. Cieza encontró Tiahuanaco ya en rúsinas y fue informado por los naturales de su antigüedad anterior a los Incas (1). El primoroso trabajo de las piedras de aparejo y su tamaño descomunal; los ídolos monolíticos de cabezas cuadradas y mirada inexpresiva; la vasta extensión de las construcciones; la puerta gigantesca de una sóla piedra ornamentada magistralmente con frisos de misteriosas figuras $y$, el hecho de hallarse estas ruinas en un paraje desolado a unos $3,625 \mathrm{~m}$. de altura, impresionó profundamente a todos los que visitaron y visitan la zona arqueológica de Tiahuanaco. Son numerosas las descripciones y especulaciones que se han hecho sobre estos misteríosos monumentos. $\bar{A}$. Posnansky, dedicó toda una vida a su estudio (2). Desgraciadamente no actuó siempre con criterios rigurosós, ên todo, sus obras se convertirán en clásicas con el tiempo, debido a la valiosa documentación gráfica recogida cuando Tiahuanaco estaba menos destruído, y a las descripciones de detalle, indudablemente valiosas en muchos casos. Posnansky derivó sus secuencias del análisis arquitectónico y del estilo de los monolitos, acotando tres períodos para Tiahuanaco (3). Sus exposiciones están inundadas de deducciones interesantes, pero construfdas sobre bases imaginarias o deleznables, que lo llevaron a afirmaciones que lo desprestigiaron. Tal el caso de la antigüedad exagerada que estima para Tiahuanaco, y su carácter de "cuna de hombre"

(1) CIEZA DE LEON, 1553, cap. CIV.

(2) Véanse sus principales obras en la lista bibliográfica que ofrecemos.

(3) POSNANSKY, 1945-57, t. 1, pp. 63-64, y sigts. 
no sólo boliviano, sino de América toda. A fines del siglo pasado, Alphons Stübel, conjuntamente con Max Uhle, realizaron exploraciones en Tiahuanaco (4). Pero en Uhle, lo valioso no está precisamente en su estudio sobre los monumentos de Tiahuanaco, en el Titicaca, sino en la identificación que realizó del estilo Tiahuanaco en la Costa, durante sus exploraciones en Pachacamac y, en el hecho de haber colocado a la cultura Tiahuanaco en el sitial, hoy aceptado y corroborado, que le toca dentro de las secuencias generales de las culturas precolombinas (5). Por otra parte, Uhle asignó a Tiahuanaco la antigüedad que se aproxima a los criterios de hoy, que difiere en millares contados con todos los dedos de la mano con las cifras de su contemporáneo A. Posnansky. También a Kroeber, se le debe importantes investigaciones y ordenación de gabinete (6).

En la década del 30 , el arqueólogo norteamericano $W$. C. Bennett hizo exploraciones y excavaciones metódicas en la región boliviana, y especialmente en el yacimiento de Tiahuanaco (7). Es. tos trabajos pusieron a descubierto varios monolitos desconocidos hasta entonces, entre los que el llamado Monolito Bennett, hoy en La Paz, figura entre los más preciados en su género (8). Con los estudios de Bennett, se aclararon algunos conceptos sobre las secuencias locales de la arqueología de Tiahuanaco $y$, en lo general, quedaron corroboradas a grandes rasgos las enseñanzas de Uhle acerca de la posición cronológica de Tiahuanaco y de su fase de expansión. Otros estudios meritorios, que sería impropio enumerar aquí póprazonés de espacio, nonhan conmovido las sólidas bases levantadas por Uhle y por Bennett (9).

(4) STUBEL UHLE, 1892

(5) UHLE, 1903, cap. X.

(o) KROEBER, 1925.

(-) BENNETT, 1934; 1936.

(8) BENNETT, 1946, pp. 109-112. (Las referencias descriptivas a las ruinas de Tiahuanaco aquí insertas, se toman especialmente de Bennett, 1946).

(9) Actualmente Ponce Sanginés realiza trabajos intensivos en Tiahuanaco, y sus primeras publicaciones ofrecen datos novedosos. Por otra parte, D. Menzel ha editado un estudio de primer orden sobre el Horizonte Medio en la Costa Sur. No comentamos estos trabajos, porque sólo han sido editados recientemente, cuando la presente manografla estaba ya en prensa. (Véase Bibliografía). 
Las ruinas del Tiahuanaco se yerguen a $21 \mathrm{Kms}$. del Lago Titicaca (3), cerca del poblaclo actual de ese nombre, sobre una altura cercana a los $4,000 \mathrm{~m}$. sobre el nivel del mar. Los monumentos se encuentran sobre una planicie desolada y de suaves pendientes, donde la vegetación es escasa, propia de las regiones de la puna, ocupando un área de aproximadamente $450 \mathrm{~m}$., medidos cle Norte a Sur, por $1,000 \mathrm{~m}$., medidos de Este a Oeste. Entre las características arquitectónicas de Tiahuanaco (10), se cuenta el uso de piedras areniscas y de basalto para formar plataformas, como se ónserva en la pirámide revestida de piedra de Acapana, el terraplén de Calasasaya, o la plataforma abierta de Puma Punco: monumentos que describiremos más adelante. Las construcciones dan efecto inonumental ila técnica observada en los aparejos consiste en la colo:ación de grandes monolitos o huancas, plantados verticalmente en intervalos, espacios que fueron rellenados con piedras de menor tamaño; la mampostería es toda una obra de arte, hecha con bloques y lajas bien labrados y cortados con simetría, llegándose a usar grampas de cobre - bronce, seqún otros autores - en las uniones; gradas líticas son comunes; se usaron en forma de complemento arquitectónico piedras esculpidas en forma de cabezas-clavas o de niedras de fachada. Bennett supone que también los monolitos, hayan estado subordinados a la arquitectura. Se usa de canales superficiales como subterráneos; aunque se dan varios pequeños cuartos subterráneos hechos de piedra labrada, Tas construcciones Subterráneas no son características de dagarquitectural de Tiahuanaco.

Las ruinas de Tiahuanaco, se considera. no representan una ciudad o población antiaua, sino un centro religioso, como lo fue Pachacamac a la llecada de los españoles, o como se sunone lo fueron también las ruinas de Chavín. Asimismo, se tiene por sonuro que su construcción obedeció a un plan general, aunque probablemente no se llevó a cabo sino a través de varias qeneraciones, quedando alqunos edificios sin terminar. Se estima que los perearinos llegaban cacla cierto tiempo del año a Tiahuanaco para colaborar en su creación. Las canteras se encuentran a distancia. Las más próximas. de piedra arenisca, están a $5 \mathrm{~km}$. de Tiahuanaco, y los blonues utilizados pesan hasta 100 toneladas; ello supone trabajo corporativo en masa. Por otra parte, el labrado de las piedras y su colocación

(10) BENNETT, 1946, pp. $110-111$. 


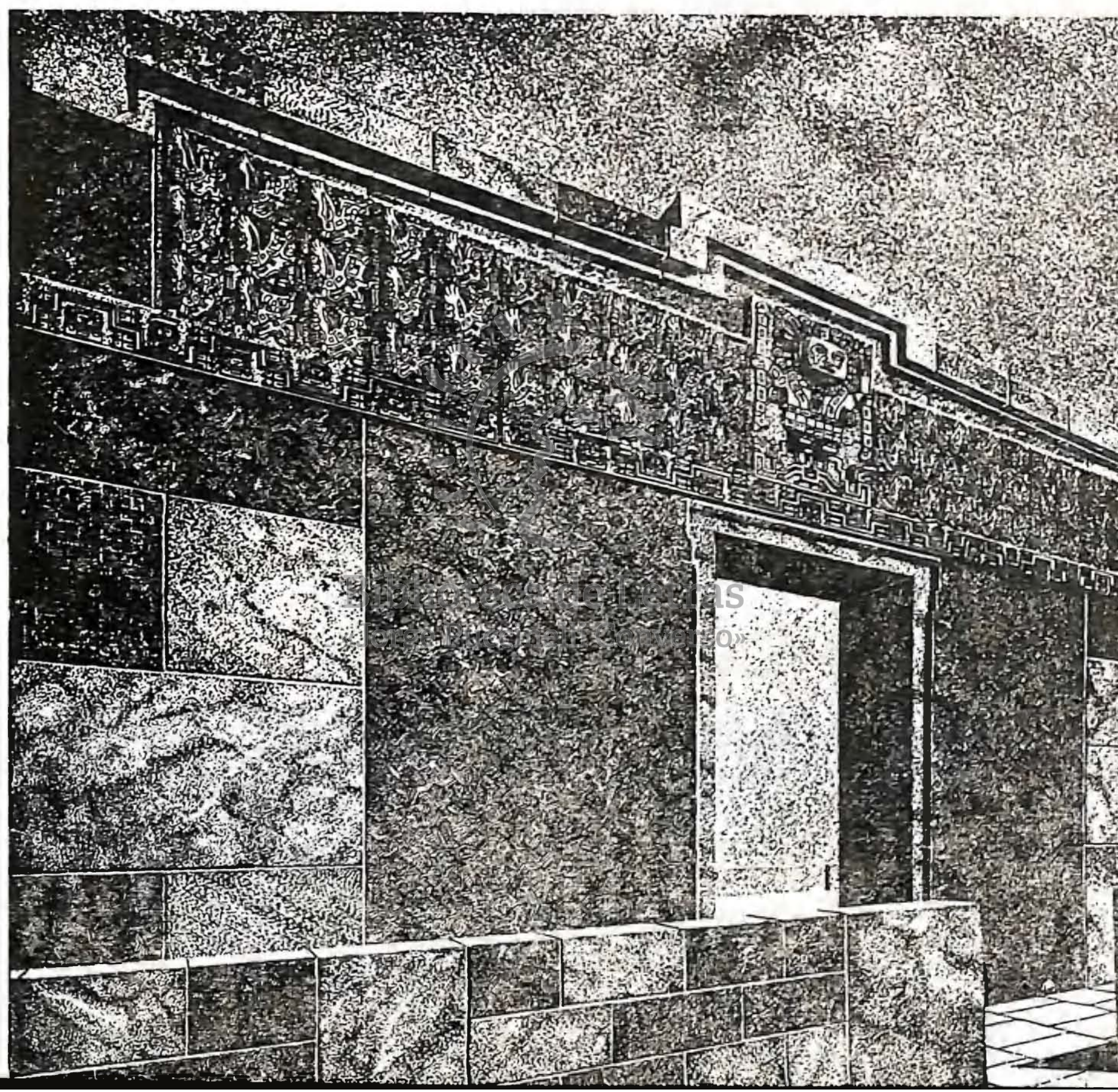


implica conocimiento de ingeniería y jerarquia para controlar la obra (11). Hay quienes atribuyen a gente de habla aymara la creación de Tiahuanaco. Pasemos revista a los principales grupos arquitectónicos de Tiahuanaco.

Acapana. La estructura principal es la que se conoce con el hombre de Acapana; se asienta sobre un montículo natural (12), y constituía antiguamente una pirámide escalonada hecha con bloques de piedra primorosamente tallados y ajustados en aparejo. Sus dimensiones son de $210 \times 210 \mathrm{~m}$. y tiene una altura de $15 \mathrm{~m}$. Se ha sugerido que Acapana se levantó con la intención de que sirviera de fortaleza o de lugar de refugio, pues en la parte superior se observa una depresión que se considera reservorio de agua con vestigios de un canal de mampostería, que Posnansky bautizó en 1904 con el nombre de "cloaca máxima" (13); hay, otras señas, que se consideran restos de viviendas y depósitos.

Calasasaya. En driección NE. de Acapana se encuentra otro grupo arquitectónico, llamado Calasasaya, que ocupa una superficie de $135 \times 130$ metros (14), marcada por monolitos labrados, plantados verticalmente en el terreno, de modo que algunos autores superficialmente creyeron ver aquí una sucesión de "menhires". Se estima que estos monolitos debieron en su origen formar un muro rectangular, con pequeñas piedras labradas interpuestas, que encerraba una plaza. A ellos alude el vocablo kalasasaya, que es aymara, significando "piedra parada", "huanca", en lengua quechua. EI área comprendida por los monolitos de Calasasaya se encuentra a cierta elevación, y en ella hay una depresión que se considera un "patio hundido", de aprx. $60 \times 61 \mathrm{~m}$. Hay acceso a esta plaza por una monumental gradería, de seis escalones, de lajas bien labradas, que se conservan en buen estado; queda ubicada en la sección media de la pared occidental. La finalidad de Kalasasaya es hasta ahora nebulosa. Se sospecha que no llegó a ser terminada esta construcción,

(ii) BENNETT, 1946, pp. 112.

(12) El nombre Acapana significa "cerro artificial", según Ponsansky (194557, t. I, p. 69).

(13) POSNANSKY, 1945-57, t. I, p. 74-76.

(14) Las medidas dadas por Ponsnansky son las siguientes: $128.74 \mathrm{~m}$. $\mathrm{X}$ 118.26 m., pero no incluyen "la pared balconera", que sitúa en su III Período. (Ob. cit., t. I, p.84). 
como indudablemente no lo fueron los frisos de la "Puerta del Sol", que se halla en sus perímetros. Hay convencidos, especialmente Posnansky, que consideran esta estructura un observatorio solar, para determinar las estaciones del año (15). En una de las esquinas de Kalasasaya se encuentra la llamada Portada del Sol, a la que nos habremos de referir más adelante, y otros monolitos grabados.

El Palacio. Con este nombre y también Palacio de los Sarcófagos, se conoce otra estructura improtante de Tiahuanaco, aunque menor en proporciones que las dos anteriores. Mide $60 \mathrm{~m}$. por $55 \mathrm{~m}$. y antiguamente estuvo circundada por un muro doble. Se encuentra a pocos metros, y hacia el lado occidental de Calasasaya.

La Estructura Posnansky y el Monolito Bennett. Demos este nombre, en honor de Arthur Posnansky, a una estructura doble, aparentemente sin nombre conocido, que se encuentra al este de Calasasaya, es decir al frente de da escalinata monolítica y a $25 \mathrm{~m}$. de la misma. Mide $21 \times 22 \mathrm{~m}$. Esta estructura, es semisubterránea y su fachada alrededor, está constituida por piedras paradas o huancas y piedras pequeñas. Algunas clavas o piedras representando cabezas estuvieron insertadas en los muros. En la sección sur de la Estructura Posnansky, halló Bennet en 1932, un monolito de formidables proporciones $(7.30 \mathrm{~m}$. de altura), trasladado posteriormente a La Paz, y que hoy lleva el nombre de su descubridor (16). Se trata de una estatua representando de cuerpo entero a un personaje. La superficie

(15) "Estas determinaciones sólo fueron posibles, mediante un edificio orientado con precisión en el meridiano y cuyo largo y ancho se hallaban ajustados al ángulo máximo de la declinación del Sol entre los dos solsticios" (Posnansky, Ob. cit., t. 1, p. 54 y sigst.) Esta suposición de Posnansky trajo consigo mediciones astronómicas hechas en algunos casos por verdaderas autordiades, especialmente destinadas a medir variantes astronómicas experimentadas con el transcurso del tiempo, con lo que se llegó a afirmar, en parte, la antigüedad de 7,000 y hasta 14,000 años de Kalasasaya. Estas opiniones no merecen crédito por hoy, pues están en completo desacuerdo con múltiples pruebas proporcionadas por los métodos arqueológicos.

(16) Walter Lehmann fue quien difundió el nombre Bennett, para nominar el monolito en mención. Posnansky y otros solfan referirse a esta piedra como el "Gran Idolo", y el propio Bennett lo nombraba "Gran Monolito". 

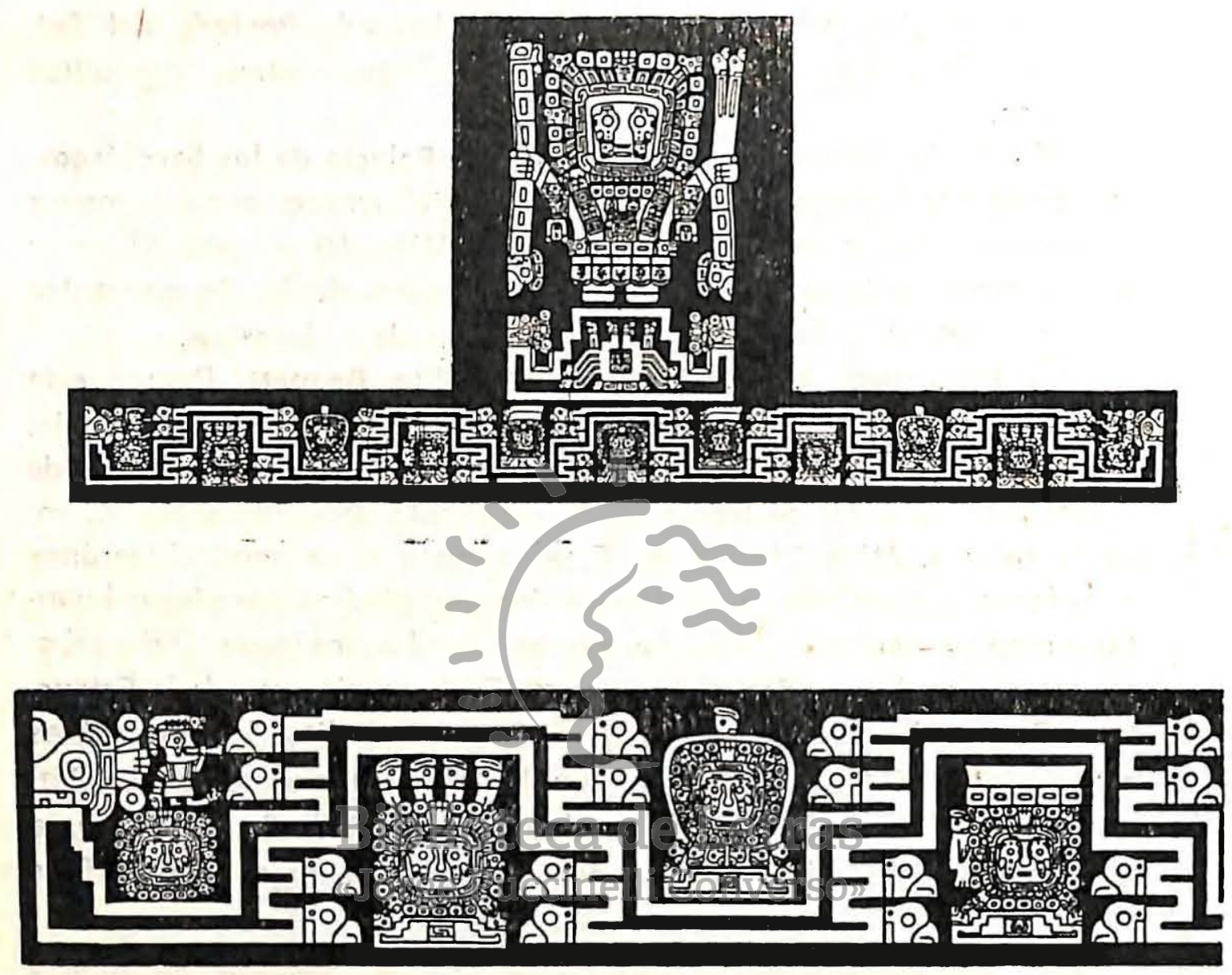

$y$

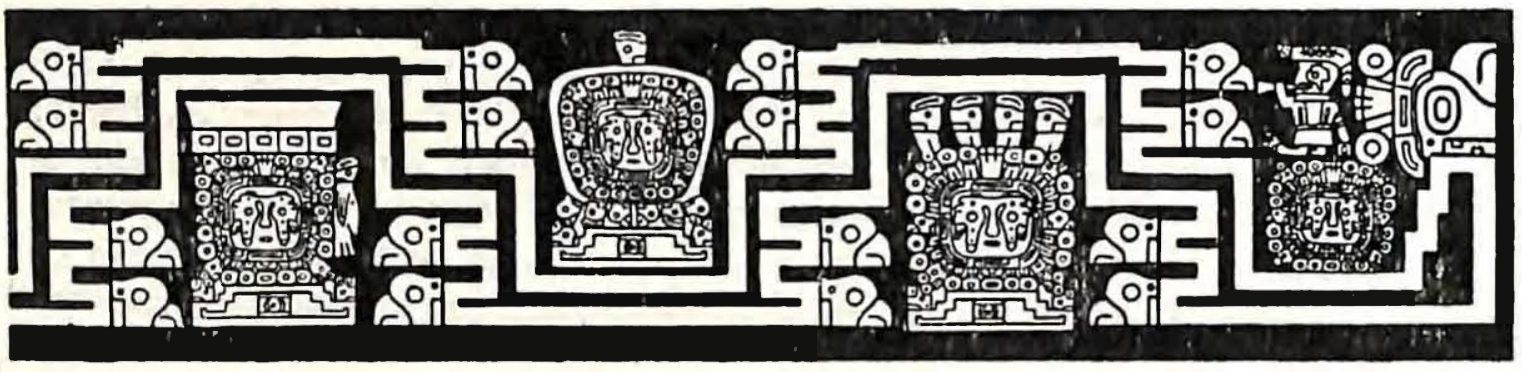

Detalles visibles en la "Portada del Sol" (Según A. Posnansky). 


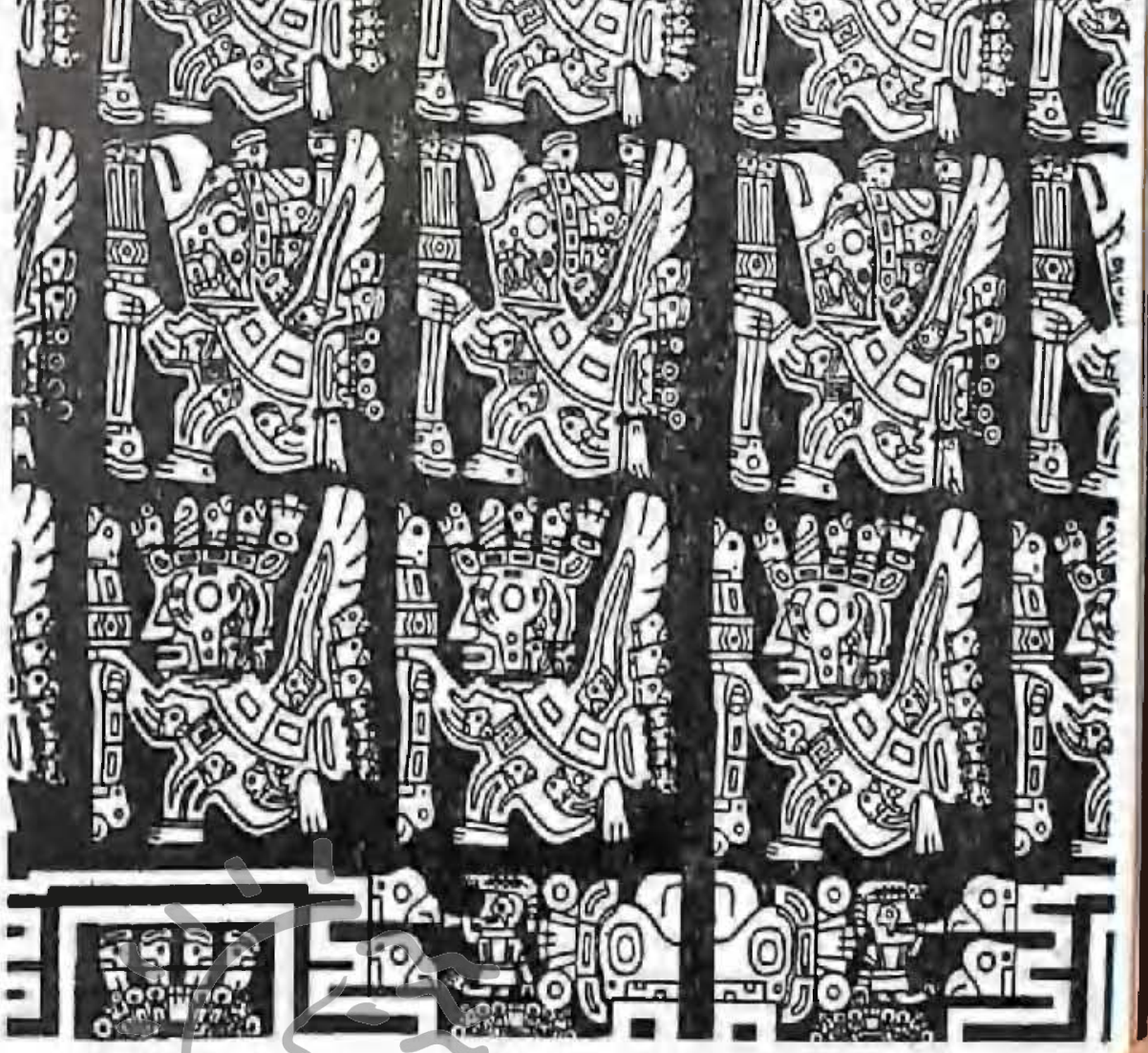

Los "seres alados" que aparecen a la derecha e izquierda del personaje central de la "Portada del Sol"' (A. Posnansky

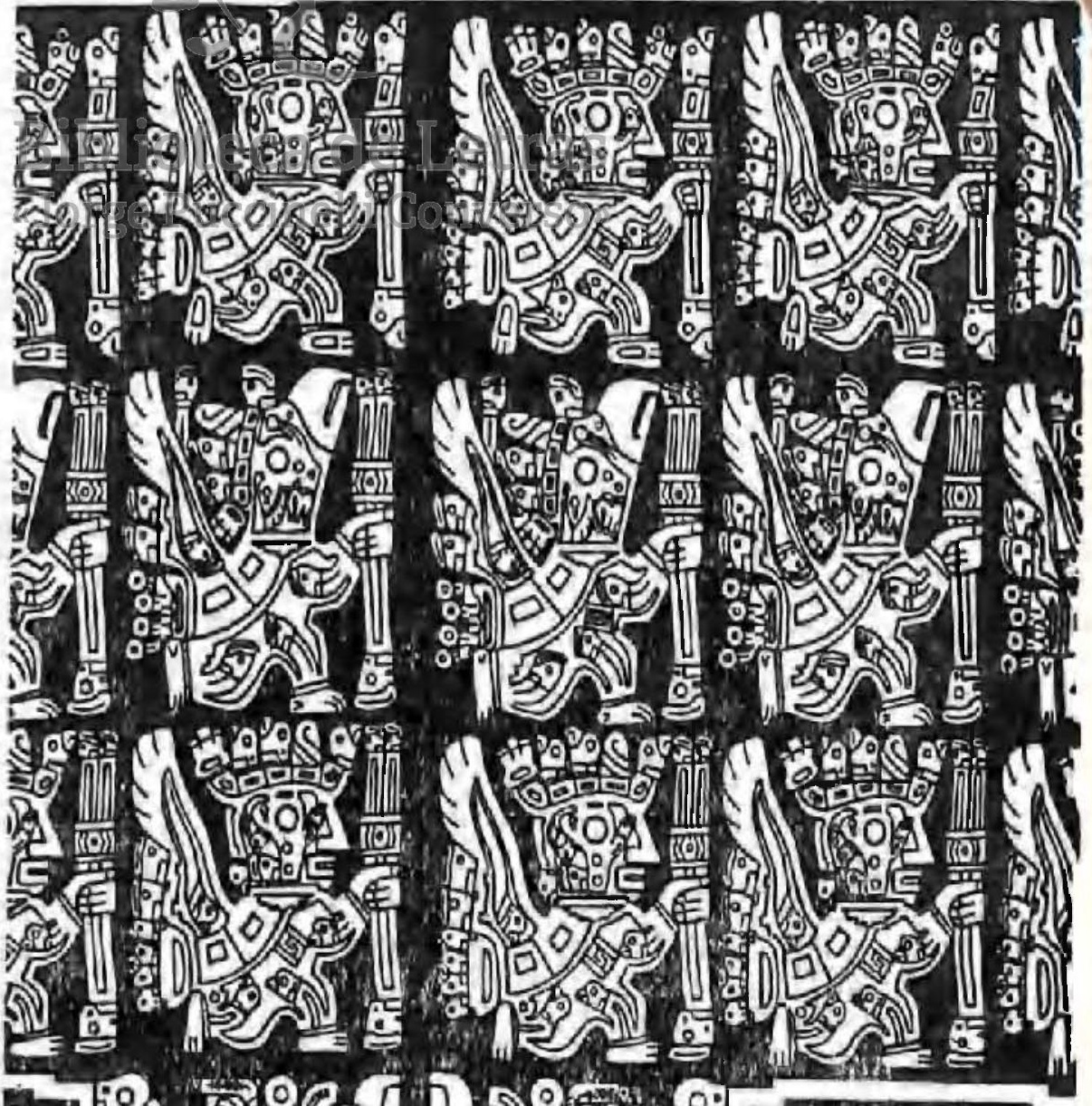


está grabada con motivos, al estilo clásico de Tiahuanaco (17). Posnansky, creyó que la estructura que lleva su nombre, pertenecía a un periodo primitivo, y defendió su tesis valientemente hasta su muerte. La opinión general, que parte de Bennett (18), es que tiene la apariencia más bien de una construcción tardía, para la cual se reunieron piedras labradas y monolitos de otras ruinas ubicadas dentro del perímetro de Tiahuanaco. (18a).

Puma Punco. La estructura de Puma Punco de $45 \times 16 \mathrm{~m}$., queda a cierta distancia del núcleo principal de las ruinas de Tiahuanaco. Se le llama Puma Punco, (portada del puma, quechua), debido que cerca de su perímetro se encuentran diversas portadas monolíticas destrozadas, aunque ninguna en proporciones y trabajo como la portada del Sol (19). Consiste en varias plataformas, formadas por grandes bloques de piedra, dos de los cuales son considerados los de mayor tamaño en todo Tiahuanaco.

\section{2. - La "Portada del Sol" de Kalasasaya y el arte lítico de Tiahuanaco.}

La llamada Portada del Sol, es, seguramente, la más célebre entre las piedras esculpidas y grabadas de Tiahuanaco. Consiste en un bloque de andesita primorosamente labrado, de aproximadamente $4 \mathrm{~m}$. de ancho por 3 de alto, en cuyo centro se ha abierto un vano o puerta. Pero no sólo concita interés por la condición monolítica que observa esta portada, ni sólo por su tamaño, sino por los frisos que aparecen esculpidos en la parte superior de la misma. En estos se representa un personaje central de talla enana y gran cabeza, de la que irradian diversos apénidices idelgadosralgunos de los cuales, alternadamente, rematan en cabezas estilizadas de cóndor. Este personaje principal, mira de frente, y sostiene en cada mano, de cuatro dedos, una especie de cetros que terminan en cabezas de ave, también estilizadas. No se remarcan los pies del ídolo, pero parece estar parado sobre un pedestal o trono, que desciende formando el llamado "signo escalonado" (frontisp.). Después de descender, estos trazos, ascienden a ambos lados a modo de apéndices (i7) BENNETT, 1934, pp. 429-439.

(18) BENNETT, 1946, p. 110.

(18a) Ponce Sanginés realiza al preser,te, excavaciones en este sitio -y restauraciones- que llevan a concepciones novedosas, que no podremos comentar en esta oportunidad (véase Bibliografía).

(19) Posnansky (Ob. cit., t. I, p. 85), aunque sin consistencia, considera a Puma Punco como "templo de la Luna". Estima que una de sus secciones fue un "establo de pumas sagrados" (Ob. cit., v. I, p. 138). 
que rematan en cabezas; la zona interior desmarcada por el pedestai en escalones en torma de pirámide trunca -tıgura tan común en la arquitecutra peruana antigua_ esta tambien escuipicia con un trazo rectangular, interrumpido en la parte superior antes cie cerrarse del todo. Da la impresion, el pedestal en conjunto, de corte estilizado de una piramide truncada de $3 \circ 4$ platatormas con una cavidad central o galeria subterránea. El personaje central está acompañado, hacia ambos lados, por 3 hileras horızontales, que solo ascienden hasta la altura de su nariz, y que representan tiguras de seres antropomorios alados (hilera central) y cóndores alados también, todos los cuales se dirigen con un bastón o cetro hacia ei personaje central. Cada una de las tres hileras que se presentan hacia ambos lados del personaje central, formando de este modo 6 grupos, están constituidas por 8 figuras independientes, formando, por lo tanto, 48 motivos en total. Debajo de la hilera izquiercia y derecha inferior, hay una más, continuada, pues se extiende por debajo de la figura central y su pedestal. Esta última hilera, muestra estilizaciones más complicadas, en su centro destaca la cabeza del personaje central con sus irradiaciones, en campos delimitados por lineas dobles y rectas siguiendo escalones en sus trazos verticales. De estas líneas dobles se desprenden apéndices que rematan en cabezas ornitomorfas, probablemente cóndores hembras ya que no observan signos de cresta. Se nota en conjunto un plan previo en la elaboración del dibujo y una marcada orientacion por la simetria y la estilización moderadalós trazos frectos han hecho pensar en patrones textiles. Siñ embargo no se hárencontrado telas en Tiahuanaco (del Titicaca), debido a que el clima no favorece su conservación. Muchas son las deducciones que se han derivado de la observación del dibujo de la Portada, del Sol, pero ninguna ha conseguido lanzar la última palabra. Se representa un simbolismo intrincado, en el que algunos han querido descubrir un calendario. Aunque es imprudente profetizar, la idea en sí -no las deducciones pormenorizadas - no parece tan descabellada, especialmente nó, si recordamos cuán ligado estuvo el antiguo peruano a la tierra y su explotación $y$, por consiguiente, a la observación de los cambios de clima en las estaciones del año.

Las referencias a los famosos monolitos de Tiahuanaco son múltiples y tan antiguas que se remiten a la primera mitad del siglo $X V I$. Los primeros dibujos sobre ellos se encuentran en las obras 


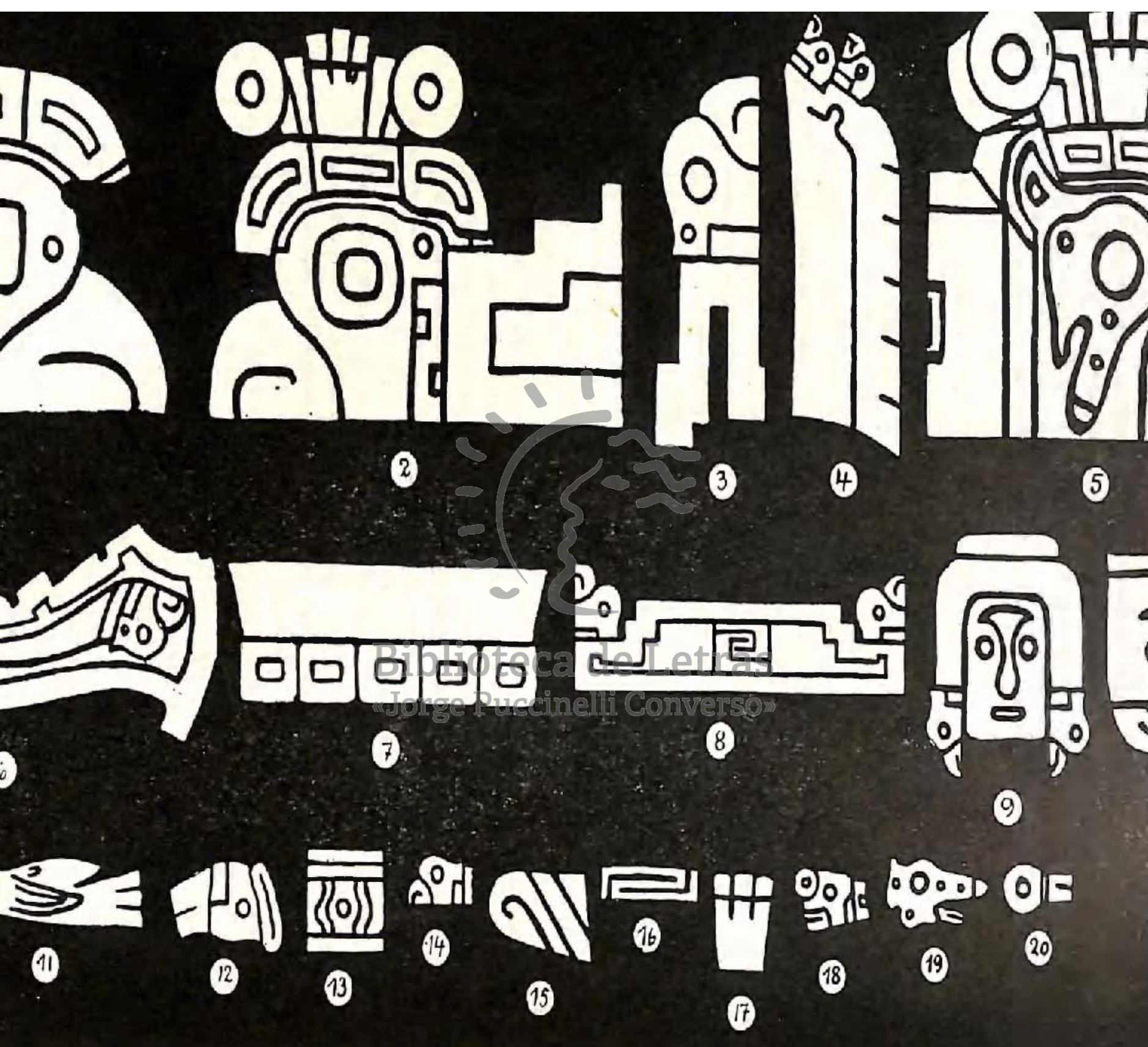

Elementos onlrasecados de les figures visibles on lo "Portude dal Sol". 


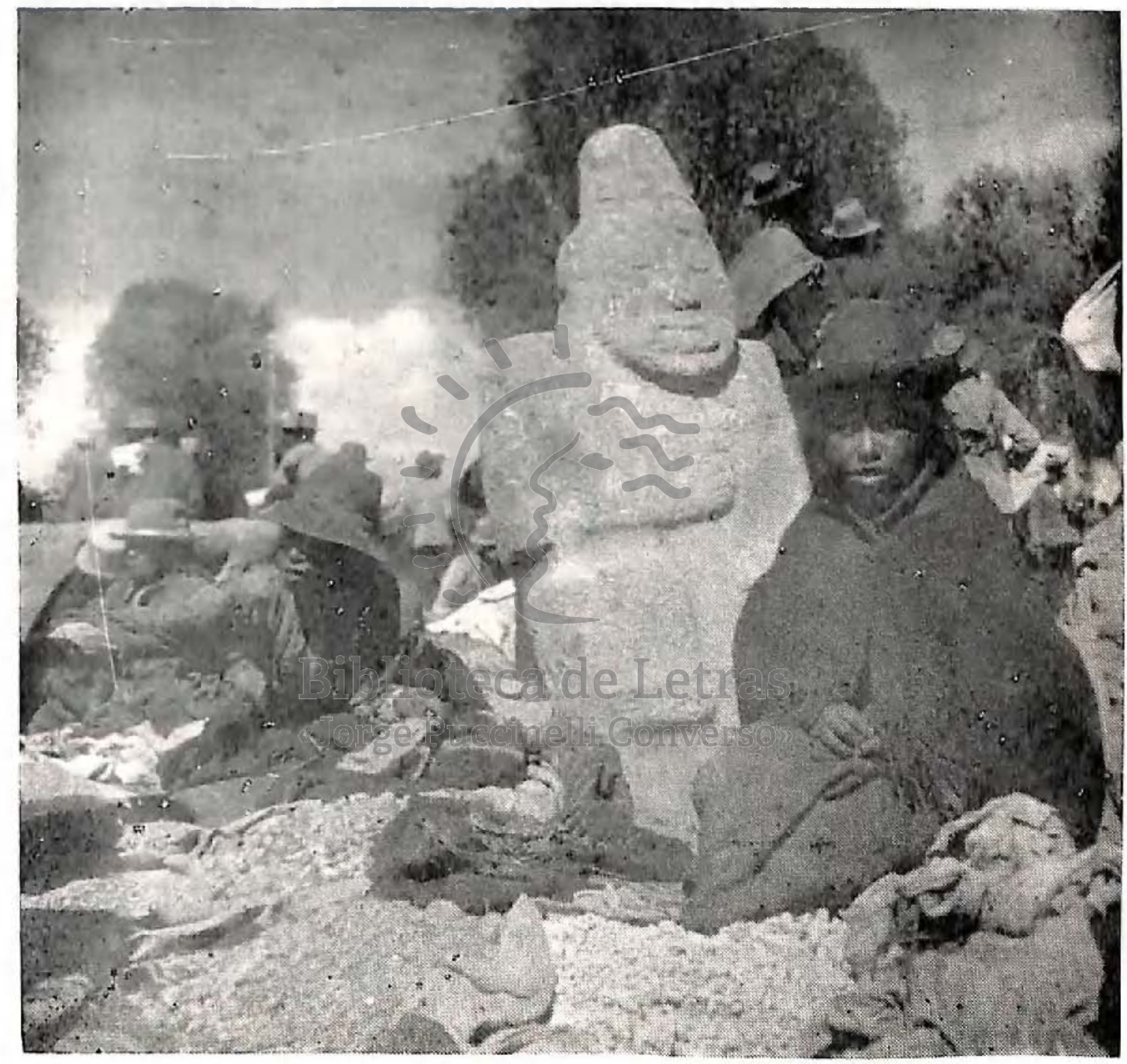

Un monolito de piedra, en la Plaza de Taraco, en las inmediaciones del Titicaca. No ha quedado establecido si la litica de Taraco tiene, y hasta que grado, relaciones con los monolitos de Tiahuanaco. 


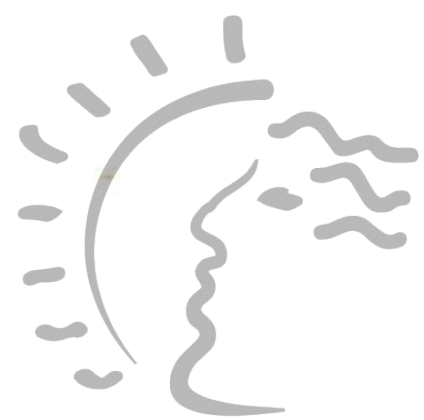

Biblioteca de Letras "Jorge Puccinelli Converso" 
de d'Orbigny, Rivero-Tschudi, Tschudi, Squier, Middendorf, etc. Stübel y Uible proporcionan un inventario gráfico y descriptivo notable, después de sus exploraciones en el yacimiento, el año $187 \%$. De mucho valor gráfico $y$ aún descriptivo, son las minuciosas descripciones de Posnansky, ya en nuestro siglo (20). Markham dedicó un estudio comparativo, sobre el dibujo de la Portada del Sol y el de la Estela Raimondi (21). Means, consideró que el de la piedra de Chuvin era un derivacio de Tiahuanaco por ofrecer trazos más elaborados y "barrocos" (22). Pero quien presenta un cuadro metódico de los mismos es Eennett (23), a través de algunos hallazgos propios, de lo que pudo observar ciurante sus exploraciones en Bolivia, tn $1932, y$ a base de leferencias gráficas diversas.

Los nejores exponentes de la lítica Tiahuanaco son, sin lugar a duda, la Portada del Sol y el Monolito Bennett, que se asocian al clásjco estilo Tiahuanaco. En la obra de Bennett, se proporciona una lista de 41 piezas líticas Tiahuanaco, con referencias a su ubicación - a la obra cionde aparecen reproducidas (24). Las agrupa en 8 diferentes estilos, pero no todos son asignados a la fase clásica de Tiahuanaco; los hay del Tiahuanaco Temprano, como de tiempos post-tiahuanaquenses de tipo decadente, que Posnansky consideraba como primitivos. Los estilos en mención son los siguientes: 1') Estatuas clásicas de monolitos; especialmente representadas por el Monolito Bennett (véase págs. anteriores), de dimensiones que oscilan entre 2.05 y $5.50 \mathrm{mi}$ en ialturac $2^{\circ}$ ) Virācocha Portada del Sol, el tipo que distingue especialmente este estilo es la figura central de la Portada del Sol." Este motivo se graba en relieves, sobre uno de los lados de grandes lápidas de andesita (véase la clescripción en págs. anteriores); $3^{\circ}$ ) Estatuas cuadradas de tipo pilar; consideradas como formas decadentes del estilo 1\%; 4\%) Figuras escultóricas con cabeza de animal. Estas estatuas reposan arrodilladas o sentadas; $5 \circ$ ) Figuras escultóricas humanas arrodilladas; el arquetipo de las mismas se encuentra en las dos estatuas que se hallan en la entrada a la iglesia de Tiahuanaco; interpretadas de modo más raturalista

\footnotetext{
( 20$)$ POSNANSKY, 1912; 1914; $1945-57$ (especialmente).

(21) MARKHAM, 1910.

(22) MEANS, 1931, pp. 138-145.

(23) BENNETT, 1934 , pp. 428-444; 460.475.

(24) BENNETT, 1934, pp, 460-463.
} 


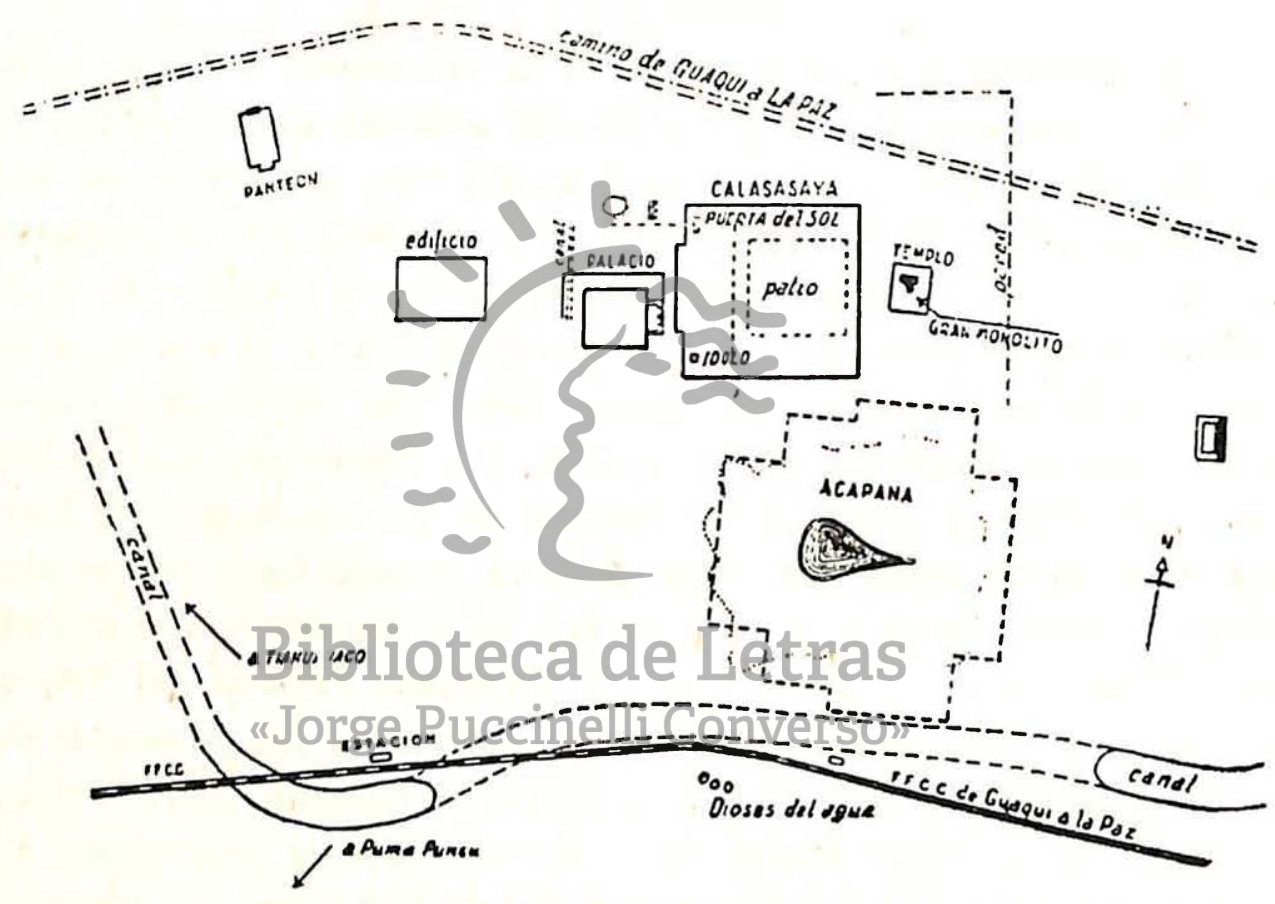

Plano de las ruinas de Tiahuanaco (De Bennett, basado en el de A. Posnansky). 
que otros monolitos de Tiahuanaco; 6?) Cabezas iiticas; hay varios subestilos, hasta seis, de este grupo, con diferencias cronológicas: a) Cabezas (Headband Type), con acabado técnico y estilístico, que se relacionan con las formas clásicas del estilo "10". b) Piedras lisas con caras; simples, que apenas si deben clasificarse de "estatuas". c) Cabezas reclondeadas (Ronded boulder hads), hechos en piedras, redondeadas, poco modificadas; se parecen al tipo " $b$ " y no tienen trazas de tener relación con las ruinas y se consideran de una fase post-Tiahuanaco; d) Cabezas con caras modeladas; realistas pero poco pronunciadas o redondeadas; llamados "retratos" por Fosnansky. Tienen su proyección para ser insertadas en los muros; e) Cabezas de esquina; las cuatro conocidas, en alto-relieve y escultura, son idénticas, y fueron halladas por George Courty (25) en la entrada a los "altares" en la parte externa de la esquina NE. de Calasasaya. Hay algunas otras piedras clel tipo que Bennett considera probablemente asociadas a este sub-estilo; $7^{\circ}$ ) Lagarto, Salamandra, - Sapo. Semeja un renacuajo y está grabado en alto relieve en piedra burda. El trabajo es técnicamente descuidado y si no fuera por el. motivo singular, hubiera sido incluido en los sub-estilos $6 \mathrm{~b}$ y 6c; 8 :) Motivos geomériricos; su nombre proviene de los grabados geométricos, hechos sobre monolitos llanos.

A base de este análisis que hace Bennett de la lítica que presenta el yacimiento de Tiahuanaco, agrupa-el arte lítico en 4 categorías (26). Las-señaladas con 4, 41 y 41 , qas considera por su tipología, tentativamente Łomololsúcesivase(Tiahuanaco Temprano, Tiahuanaco Clásico y Tiahuanaco Decadente) en el tiempo; la categoría IV, la considera posterior a II, kero duda de si es anterior a III, coetánea o posterior a la misma.

GRUPO I: Lítica realista (Estilos 5, 6b y cabeza de puma de 6a).

GRUPO II: Talles y cabezas clásicas convencionales (Estilos 1, $2,4,6 a)$.

GRUPO III: Estátuas y cabezas de tipo pilar técnicamente decadentes (Estilos 3, 6b, 6c, 7).

GRUPO IV: De diseños geométricos (Estilos 6e, 8).

(25) CREQUI-MONTFORT, 1906, p. 541.

(26) BENNETT, 1934, pp. 474- 475; 1946, p. 111. 

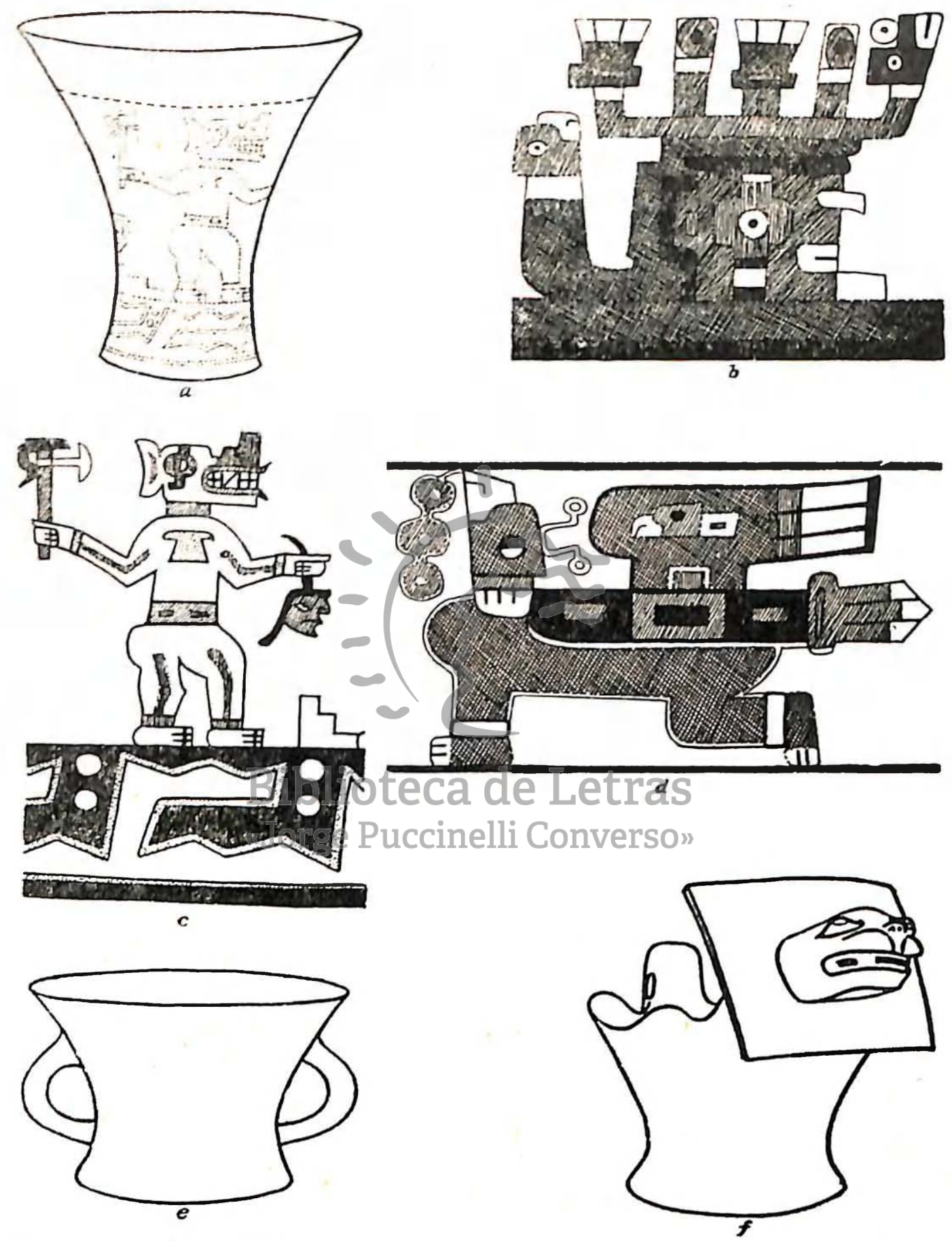

Formas y motivos clásicos de cerámica Tiahuanaco hallada en el yacimiento de este nombre, en el Titicaca. Dibujo, según Bennett. 


\section{3.-La cerámica "Tiehuanaco Clásico", (Titicaca).}

Mientras que Posnansky fundaba sus secuencias culturales de Tiahuanaco sobre observaciones arquitectónicas, Bennett, durante sus exploraciones de 1932, prefirió realizar excavaciones destinadas a rastrear el desarrollo cultural estratigráficamente, basándose en la cerámica (27). Y es a Bennett (28), a quien debemos el análisis más detallado y sistemático de la alfarería Tiahuanaco (29). Este pervanista dió la siguiente secuencia alfarera para el yacimiento de Tiahuanaco: Tiahuanaco Temprano, Tiahuanaco Clásico, Tiahuanaco Decadente, y Post-Tiahuanaco (30). La cerámica calificada como Tiahuanaco Clásico, llamada por otros también Tiahuanaco Boliviano, es la que está asociada intimamente a las expresiones arquitectónicas y líticas de Tiahuanaco e, indirectamente, a las variedades del estilo Tiahuanaco de expansión panperuana. Se considera que el tipo Tiahuanaco Clásico tiene un área limitada, circunscrita muy especialmente al yacimiento epónimo. En cambio, Tiahuanaco Decadente, está diseminado por un área geográfica considerable.

Entre las formas más comunes, (tipo $A, B, C, D$ y $E$, de Bennett), la más típica es la que se conoce con el nombre de quero (31); un vaso cilíndrico con boca más ancha que la zona de la base. Esta forma se presenta tambiére en la expansión del estilo y adopta a veces variantes notables, como cuando se estrecha en la base. La forma B, de Bennett, puede considerarse como una variante de la

(27) BENNETT, 1934, pp. 369-391; 445-459. (Excavó en total 10 pozos, cada uno de ellos no podía exceder en su superficie $10 \mathrm{~m} 2$., según lo reqlamentado por el Gobierno de Bolivia).

(28) BENNETT, 1934, pp. 392-424, 476 y sigts.

(29) Sólo Courty, a principios del siqlo, hace alusión a cerámica de tipo Tiahuanaco encontrada estratiaráficamente, debajo de tumbas aymaras. (Véase: CREQUI-MONTFORT, 1906, p. 66).

(30) BENNETT, 1934, pp. 476-478.

(31) Con la palabra quero se designa en especial el vaso de libaciones de madera de la época Inca y post-Inca inmediata, que se encuentra con profusión en la región del Cuzco. La froma campanular del quero Inca, ha motivado que algunos autores llamen de hecho quero, por la forma y no por el material, a la cerámica Tiahuanaco que observa esta característica, unidas a otras típicas al quero de madera. 


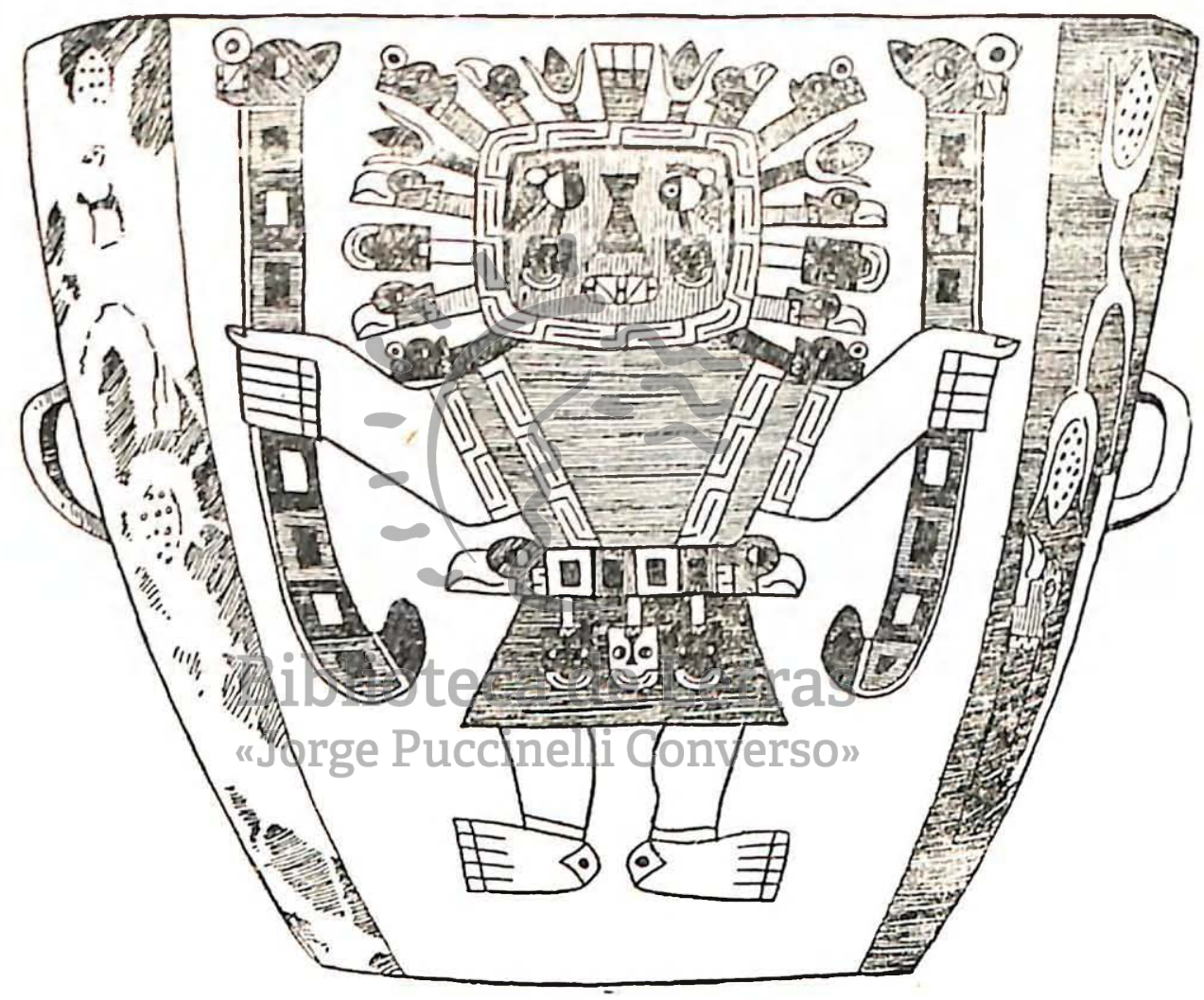

Pieza cie cerúmica clel tipo conocido con el nombre PACHECO. Repiesenta un tipo Tiahuanaco puro, presente en la Costa Sur. 
anterior, pero tiene su base cóncava, a diferencia de la del tipo anterior, por lo que forma en realidad una taza. La forma $S$ con asas verticales suele considerarse típica, como también las variantes en que los bordes aparecen recortados $u$ ondulantes mientras que en un extremo remata en una cabeza escultórica, hueca en su interior, especialmente de felino, en la que aparece traspasado un marco cuadrado a manera de collar. Los pies y la cola del animal destacan también en relieve. La forma $C$, corresponde a una taza campanular, en algunos casos con prominencia ancha cerca de la base, invariablemente asociada con los diseños típicos del Tiahuanaco clásico (32). La forma D se refiere a cántaros "globulares" altos, de boca expandida. El tipo $E$ consiste en tazas a manera del tipo A, pero cortado por la mitad. Esta forma es muy frecuente en la etapa Decadente, pero se considera que el origen de esta forma se da en Tiahuanaco clásico.

Las piezas decoradas están hechas de arcilla fina temperada con arena, y frecuentemente con mica; fueron modeladas y también fabricadas en molde. Las combinaciones en el colorido más usuales son: negro, blanco, amarillo, y gris sobre rojo. Los colores son de gran viveza y su aplicación se hace sobre engobe o sobre fondo rojo. El pulimento es de bueno a execelente. Los diseños aparecen contorneados en negro y con tendencia realista, observando variantes limitadas a: una figura completa de un felino o un felino con cabeza de cóndor, un cóndor, y una figura humana o cabeza. Los diseños geométricos presentan predominantementer una greca. Cuando el cuerpo aparece de frente, la cabeza y los pies suelen concebirse de costado. El diseño se repite, generalmente, alrededor de la vasija, con cambios de color (33).

\section{LA EXPANSION TIAHUANACO (HUARI)}

Como queda anotado, hasta hoy, sólo en la región del Titicaca se ha encontrado antecedentes estilísticos del estilo Tiahuanaco del Titicaca. Estos están representados por Qeya (Tiahuanaco Temprano) y Pucara. Estos estilos está emparentados, pero se considera que ninguno de los dos haya originado a otro. En todo caso, durante

(32) BENNETT, 1934, p. 455.

(33) BENNETT, 1934, pp. 453-456; 1946, pp. 114-115. 


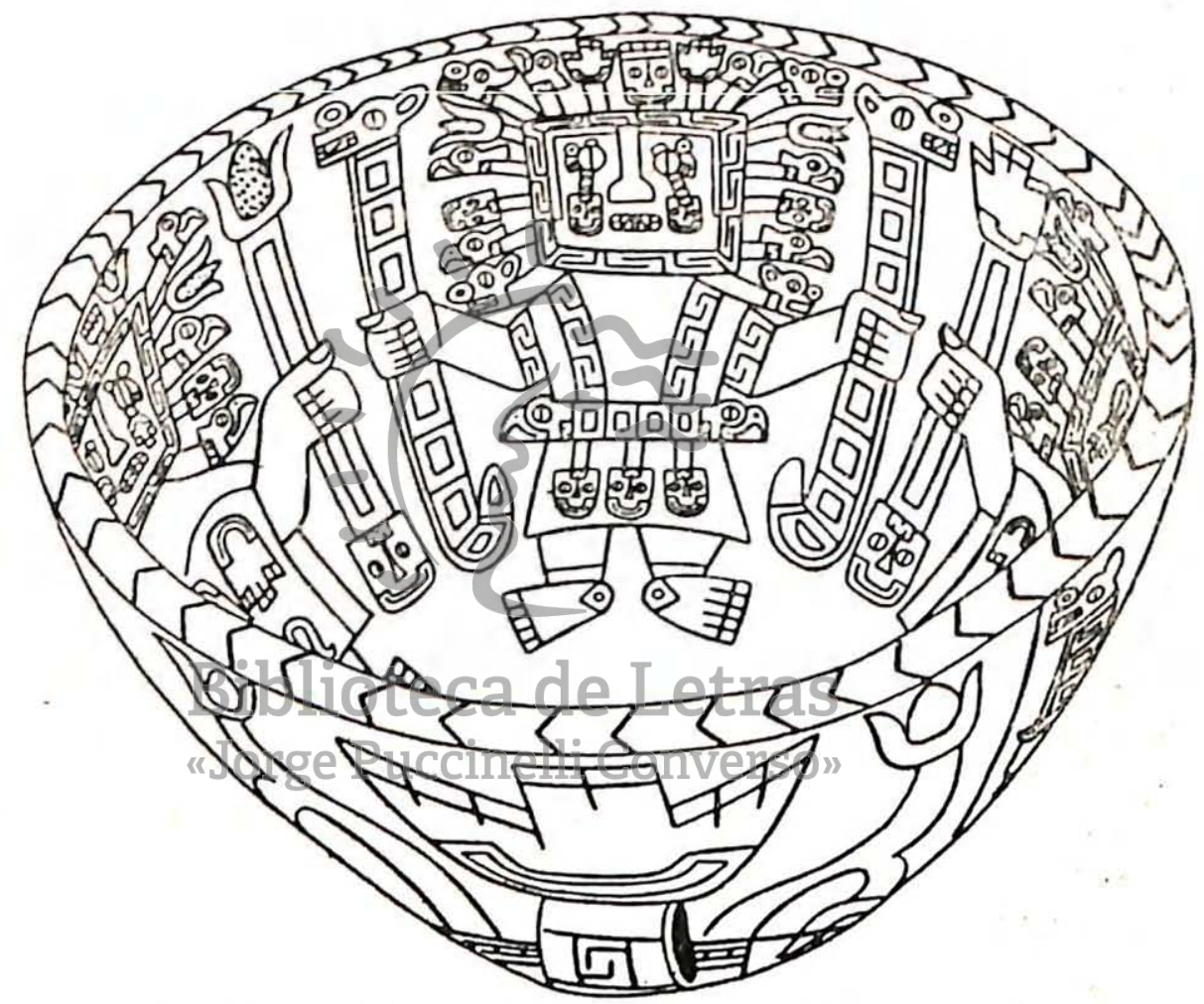

Fieza de cerámico del tipo PACHECO (Véase dibujo anterior), con ornamentación en las paredes internas (Dibujo de Pablo Carrera). 
la madurez del estilo Tiahuanaco del Titicaca, tiene lugar un fenómeno especial de trascendencia panperuana: la difusión de este estilo por diferentes regiones. No se ha podido precisar la ruta o rutas que siguió la irradiación inicial de Tiahuanaco, ni los senderos que tomó primero, ni siquiera hay constancia absoluta de que partiera del Tiahuanaco del Titicaca. Ese centro arqueológico bien pudo, también ser el resultado de ese movimiento expansionista. De pronto encontramos el estilo Tiahuanaco en la zona de Ayacucho $y$, también, en Pachacamac. Todo hace pensar que la cultura Tiahuanaco se difunde a través de un culto determinado, pues los motivos que presentan sus manifestaciones artísticas son profundamente simbólicos y rituales. Pero, aunque esto ya entra en el terreno de las suposiciones no es improbable que este culto pudiera propagarse, tan eficazmente, gracias especialmente a acciones bélicas: Un tipo de Guerra Santa, a la manera como se extendió el Islam. Desde el siglo pasado se ha pensado en un "Imperio Tiahuanaco", y se ha supuesto que éste había sido forjado por gente de habla y raza aymara. Así se explicaba la presencia por todo el Perú de toponimias con equivalentes en el Aymara. En todo caso, el culto Tiahuanaco se difundió a través de distintos aspectos culturales. En otros casos actuó como vehículo para transportar elementos culturales no originales de Tiahuanaco en el Titicaca, sino de otras zonas, donde el estilo Tiahuanaco acampó y tomó en parte tradiciones nuevas que a su vez difundió. Tahel caso, que rsescita, referente al conocimiento de un tipo urbano que habría sido llevado por lo Nasca a la región de Ayacucho, pasando a ta cultura Tiahuanaco presente luego en la zona de Ayacucho. De alli se habría dispersado a otras regiones a donde llegó a irradiar la cultura HuariTiahuanaco. Así, también, se "implantó en la costa central la costumbre de enterrar a los muertos sentados y enfardelados". En todo caso, con la expansión Tiahuanaco, y principalmente con el foco que representó Huari, se difunde una serie de conceptos por todo el área andina, que la impregnan cle denominadores comunes. En algunas zonas se impone el nuevo orden cultural sin que la tradición local pudiera sobrevivir, especialmente en regiones que hasta entonces tenían cultura incipiente como en el extremo sur del Perú y Norte de Chile y el Noroeste Argentino. Aún en el caso de la región del Cuzco, que más tarde será un centro cultural de importancia mayúscula, Rowe, se inclina a creer que hubo un reemplazo 

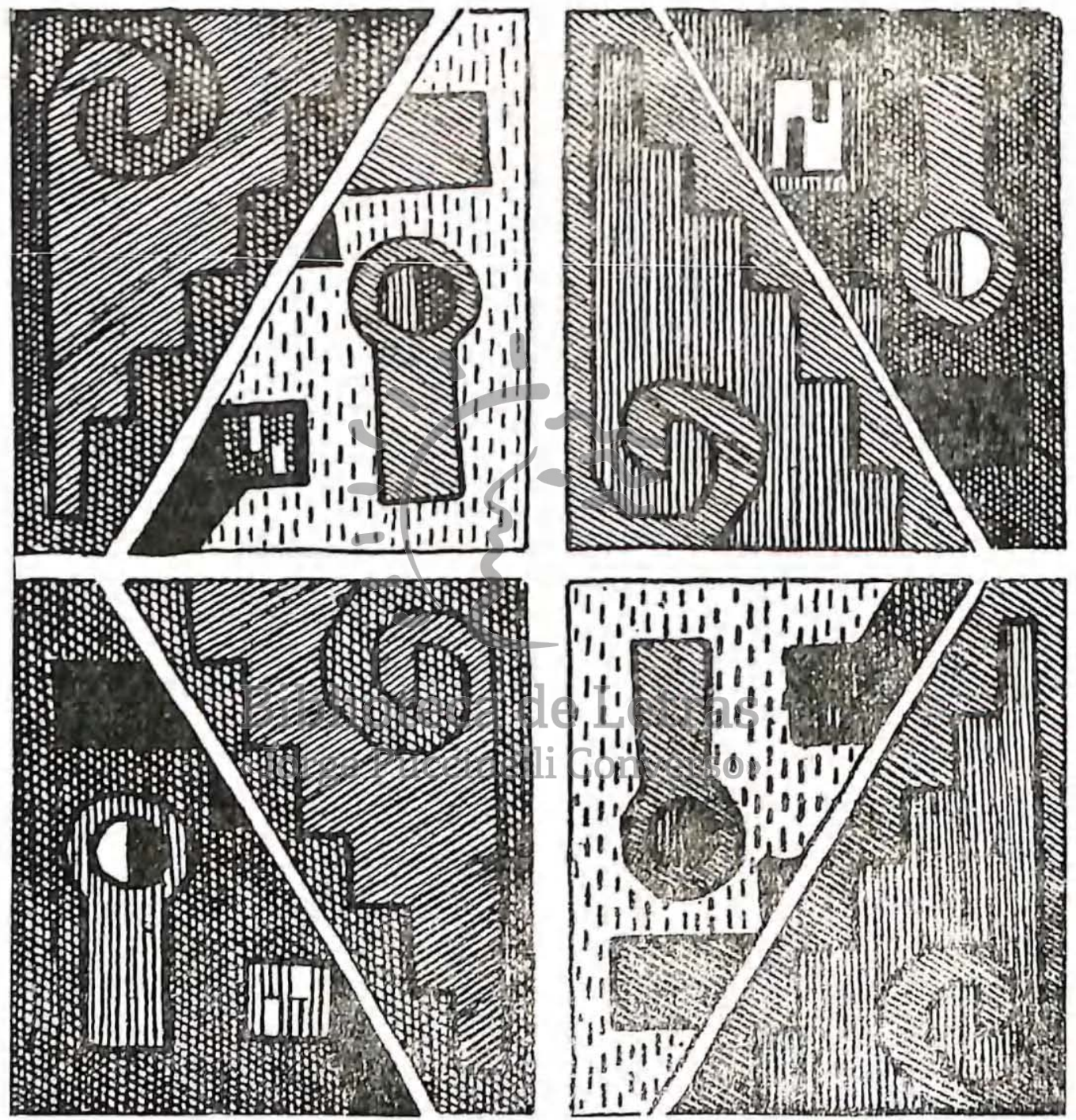

Tela "Tiahuanaco de la Costa", con figuras tiahuanaco muy estilizadas (Según E. Yakovleff). 
de una cultura por otra, considerando que "la cultura Inca tiene sus raices más importantes en las tradiciones de Ayacucho, Nasca, y posiblemente en Tiahuanaco (clásico) también, y no en las culturas más antiguas del mismo valle del Cuzco". (34). El impacto Tiahuanaco o Huari, fue menos drástico en la costa norte y Sierra Norte (Cajamarca). Nasca no le ofreció bastante resistencia, a pesar cle su personalidad definida, porque Tiahuanaco cuando llegó a su zona tradicional en la costa (región de lca), llevaba ya signos emparentados a lo Nasca, a través de la mezcla previa experimentada en Ayacucho con la base Tiahuanaco.

En Ayacucho se mezcla con la tradición local, que era a su llegada el estilo Nasca irradiado, sin o con algunos pocos elementos locales primitivos que se conocen con el nombre de Huarpa. El estilo Tiahuanaco parece hacer una "pascana" o estación, en Ayacucho y desde aquí, después de adquirir ciertas modalidades propias, por mezcla o adopción de lo Nasca ayacuchano irradia nuevamente, tornándose el lugar en foco poderoso. Este estilo Tiahuanaco irradiado primitivamente a Ayacucho y amalgamado con la tradición local Nasca, se conoce con el nombre de Huari, o, con uno ajeno a los tradicionales signos de escritura: Wari. En Huari se da estatuas líticas, pero difieren de las de Tiahuanaco. Su posición cronológica no está bien establecida, pero debe ser considerada como posterior a las últimas fases Nasca. (siglos IX 6 DC).

Por otro lado, Tiahuanaco parece llegar, no-ya por intermedio de Huari, sino directamentela Pachacamac. donde también recibe el influjo regional. En Pahacamac, empero, el estilo Tiahuanaco logra imponerse con más pureza que en Ayacucho, debido a que los estilos locales no presentaban una personalidad definida como el Nasca en Ayacucho.

El estilo Huari se difunde por la Costa Norte, Central y Sur, donde adquiere nuevas modalidades. En la sierra se le encuentra desde Cajamarca hasta Sicuani, en Puno. El estilo Tiahuanaco de Pachacamac limita su irradiación a la Costa en Dirección Norte y Sur, alcanzando su influencia hasta Supe y por el Sur hasta lca, y probablemente, hasta Nasca.

(34) ROWE (J.H.): Tiempo, estilo y proceso cultural en la arqueología peruana. Berkeley, 1960, (p. 12 ). 
El estilo Pacheco, en Nasca recibió el estilo Huari en forma pura, por importación, pues es asombroso su parecido con la cerámica ayacuchana de tipo Conchopata, que se considera una expresión Tiahuanaco de extraordinaria pureza por su paercido a los grabados de los monclitos de Tiahuanaco de Titicaca.

Por lo expuesto se da, en la Sierra y Costa peruanas, un tipo Tiahuanaco apegado a las formas clásicas, como Conchapata y $\mathrm{Pa}$ checo, y una parte de Pachacamac. Estos serían los primeros signos de la influencia de Tiahuanaco en su expansión, hasta hoy reconocidos. La amalgama con la tradición Nasca y otros estilos locales que encuentra el estilo Tiahuanaco de Tipo Huari, a su paso, representa la fase más caracteristica del estilo Tiahuanaco en su expansión. En el área de Arequipa, hasta Atacama en Chile, y en la zona del Noroeste argentino, se presenta el estilo con pureza, y supervive sin mayores influencias por un tiempo, pues la tradición local en esas era pobre. El estilo Tiahuanaco peruano con todas sus variantes pierde rápidamente, talvez a través de 2 ó 3 generaciones, sus lazos típicos. Se desprestigia y a su lado aparecen pujantes las tradiciones locales que había interrumpido. En esta fase de decadericia de Tiahuanaco, que se conoce desde Uhle también con el nombre de Epigonal, hay algunos rasgos particulares que se presentan en diversas áreas. Tal el caso del uso de tres colores para formar dibujos geométricos. $\mathrm{De}$ ahí que al Epigonal esté asociado el llamado estilo Tricolor (blanco, rojo, negro), o mejor aún Tricolor geométrico, gefocuentemente representado a lo largo de toda la Costa y la Sierra Norte. El Tricolor geométrico suele donominarse también Tiahuanaco Costeño $B$ y se considera que representa un desarrollo del litoral, ya independiente de influencias serranas. La denominación Tiahuanaco Costeño $\mathbf{A}$, alude a manifestaciones más o menos apegadas al arquetipo en Tiahuanaco clel Titicaca (35).

Prácticamente en todo el Perú se da un estrato correspondiente al horizonte Tiahuanaco. Sería largo enumerar los sitios hasta hoy reconocidos. En la Sierra Norte Huilcahuaín, es conocido como un sitio mercadamente Tiahuanaco. Yacimientos Tiahuanaco tales como Huari, Pacheco, Pachacamac, etc. han sido ya mencionados.

(35) BENNETT, 1946, pp. 125-129. 


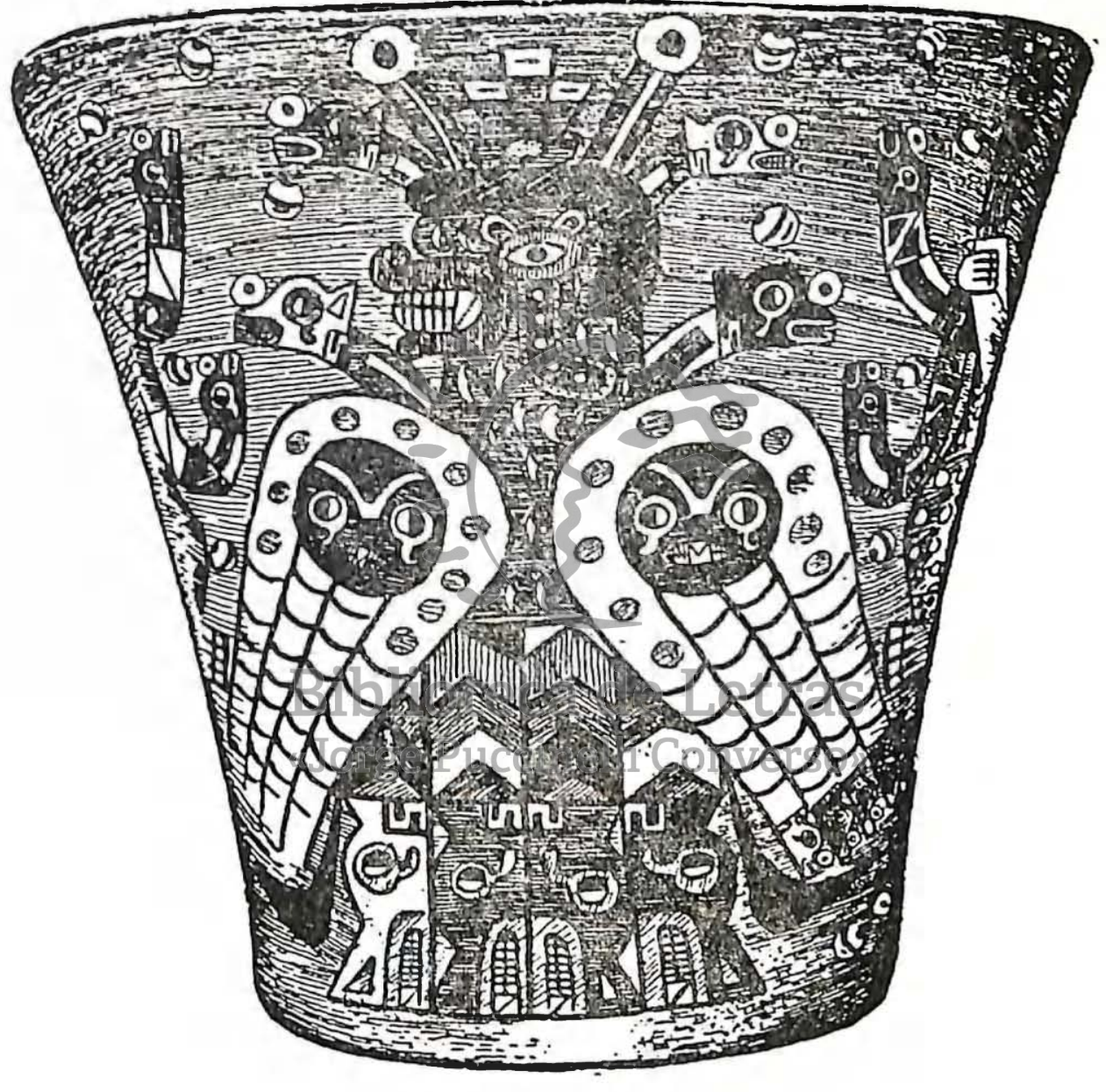

Otra muestra de vasijas tiahuanacoides presentes en la Costa Sur. 


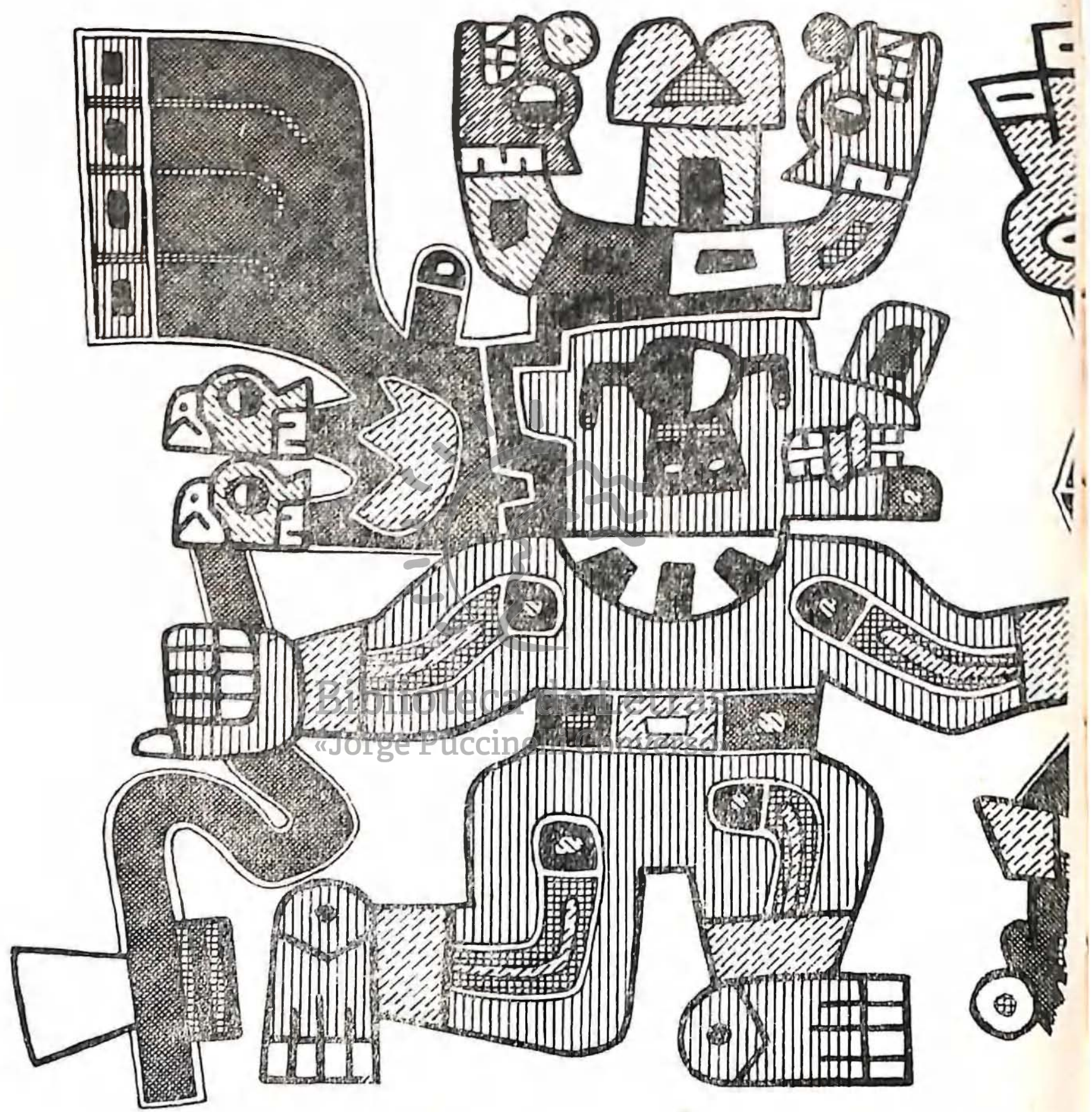

Personaje alado dibujado de una pieza de cerámica del tipo CONCHOPATA (Ayacucho) 


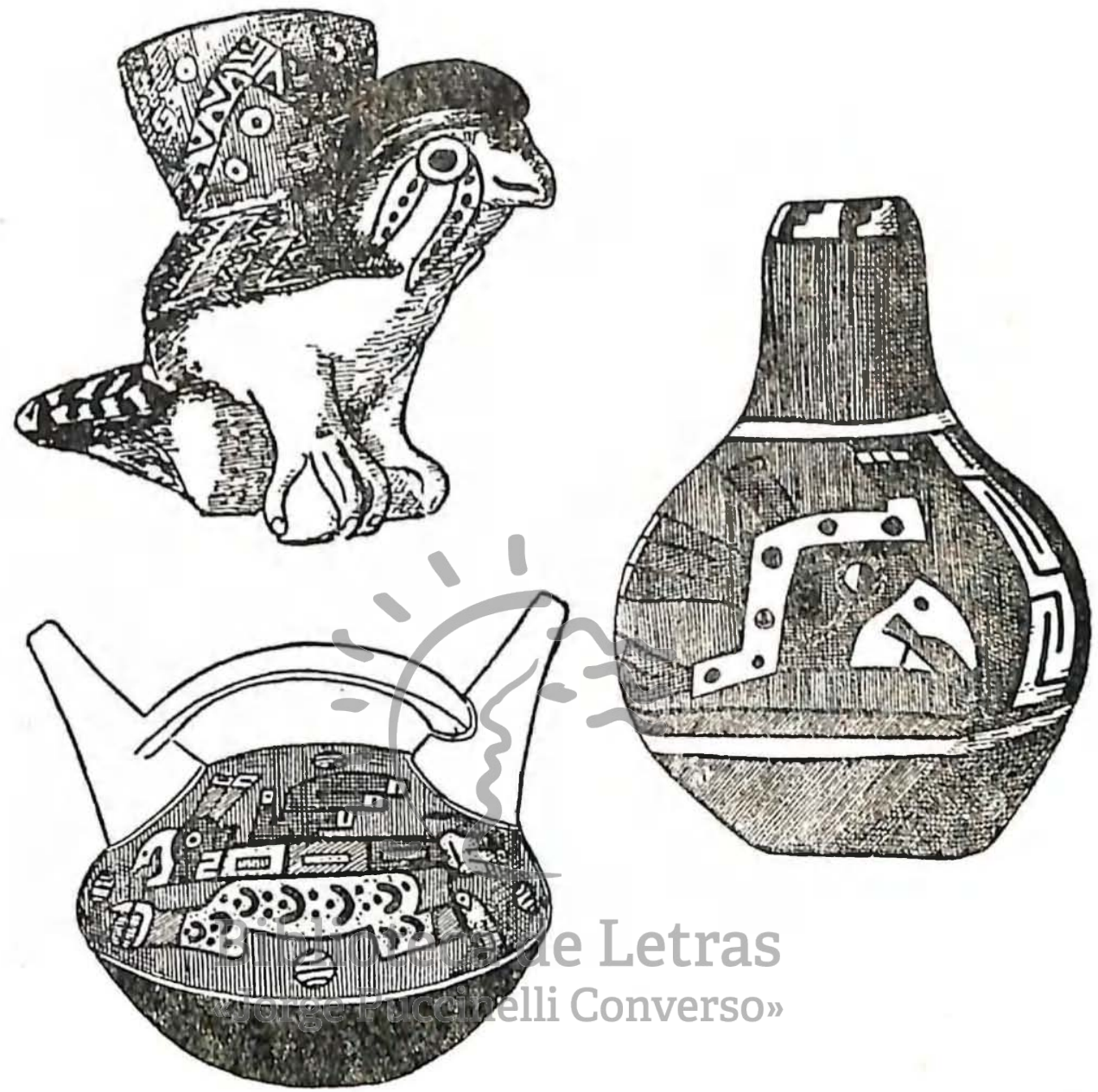

Tres vasijas tiahuanacoides (Costa Sur). Los dibujos pertenecen a E. Yakovleff.

El periodo Tiahuanaco expansivo es relativamente corto. Después de cien años o menos, se diluye el estilo Tiahuanaco y decae en formas derivadas. Simultáneamente los estilos locales "oprimidos", anteriores a Tiahuanaco, reemergen. Estas dos vetas serán las bases sobre las que se asentarán los principales estilos de la época que sigue a Tiahuanaco, y que perderán, a su vez su color local con la difusión Inca, ya en el siglo XV.

Lima, 1962. 


\section{BIBLOGRAFIA SOBRE LAS RUINAS DE TIAHUANACO $Y$ "TIAHUANACO EXPANSIVO" (HUARI; TIAHUANACOIDE) (*)}

\section{ANGRAND (Leoncio)}

1866 Lettre sur les antiquités de Tiaguanaco et l'origine présumable de la plus ancienne civilisation du Haut-Pérou. París,...

\section{BENNETT (Wendell C.)}

1934 Excavations at Tiahuanaco, Anth. Pap. Am. Mus. Nat. Hist., v. 34, Part. III. Nevs York,...

1936 Excavations in Bolivia. Anth. Pap. Am. Mus. Nat. Hist., v. 35, Part. IV New. York,...

1946 "The Central Andes". Hadbook South Am. Ind., 2 Washington,...

1953 Excavations in Wari, Ayacucho, Perú. Yale Univ. Publ. Anth., v. 49. New Haven,...

BERMUDEZ JENKINS (Adolfo)

"Fardo funerario Tiahuanaco. Colecciones del Museo". Rev. Mus. Reg. de Ica. Ica,...

BUCK (Fritz)

1937 El calendario maya en la cultura Tiahuanaco. La Paz,...

1939 Inscripciones calendarias del Perú preincaico (Sobretino Rev. Mus. Nac., 8 ) Limage Puccinelli Converso» Véase CREQUI-MONTFORT

CREQUI-MONTFORT (Count G. de)

1906 "Fouilles de la missión scientifique francaise a Tiahuanaco", XIV Int. Cong. Am. 2: 531-51. Stuttgart,...

D'ORBIGNY (Alcide)

1844 Voyage dans l'Amérique Méridionale, Tome III, Partie I, Partie Historique. París,...

(*) Con pocas excepciones, sólo la del siglo $X X$. No mencionamos aquí las muchas obras que contienen referencias a Tiahuanaco, tales como las de Rowe, Strong, etc., para no alargar esta bibliografía. Reducimos, por lo tanto, esta lista a obras çue abordan especificante el tema 'que nos ocupa. No todas las obras mencionadas han sido escritas por especialistas. 
GONZALES DE LA ROSA (Manuel)

1910 "Les Deux Tiahuanaco, leurs problémes et ieur solution". XVI Int. Congr. Am. pp. 405_28. Wien,...

IBARRA GRASSO (Dick Edgar)

1960 "Esquema arqueológico de Bolivia y relaciones con el Perú".

Antiguo Perú. Espacio y tiempo, pp. 301-308. Lima,...

KIDDER II (Alfred)

1943 Some Sarly sites in the Nortinern Lake Tifica Bansin. Papers Peab. Mus. Am. Arch. [!n., vol. 27, 1. Cambridge, Mass.,...

KISS (Edmund)

1937 Das Sonnenicr voil Tiahuanacu und Horbigers Welteislehre. Leipzig,... .

KROEBER (Alfred)

1925 The Uhle Pottery Collections from Mocine. Univ. Cal. Publ. Arch. Eth., v. 21, No 5. Berkeley...

En parte.

LANNING (Edward)

1956 The Tiahuanaco Horizon on the Coast of Peru. MS. University of California, Berkeley,...

LUMBRERAS (Luis G.)

1959 "La cultura Wari, Ayacucho". Etn. y Arq. (Publ. Inst. Etn. y Arq. Univ. San Marcos), (1:130-220. Lima,... ClaS

MARKHAM (Clemente CR:ge Puccinelli ConverSO»

1910 "A Comparison of the Ancient Peruvian Carvings and the stones of Tiahuanacu and Chavin". Int. Am. Congr. Erste Halfte, pp. 389394. Wien und Leipzig,...

MEAINS (Ph. Ainsworth)

1931 Ancient Civilizations of the Andes. New york and London, ... (véase esp. pp. 138-145).

MENZEL (Dorothy)

1958 "Problemas en el estudio del Horizonte Medio en la arqueología peruana". Rev. Mus. Reg. Ica, 10: 24-57. Ica,...

*1964 "Style and Time in the Middle Horizon". Nawpa Pacha, 2: 1-105, 9 láns. Berkeley, California,...

(*) Obra reciente, cle primera calidad. No ha sido posible comentarla en nuestra manografía, escrita inicialmente en 19ó2. Sólo podenos ofrecer la ficha bibliográfica respectiva. 


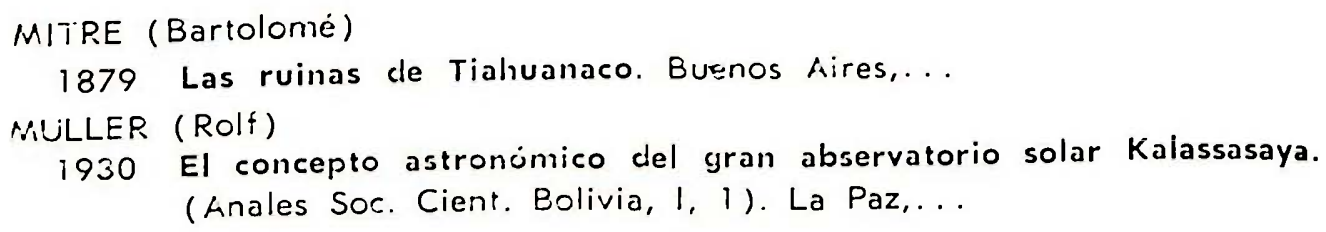

1879 Las ruinas de Tiahuanaco. Buenos Aires,...

MULLER (Rolf)

1930 El concepto astronómico del gran abservatorio solar Kalassasaya. (Anales Soc. Cient. Bolivia, 1, 1). La Paz,...

VVESTLER

1913 Beitrage zur Kenntniss der Ruinenstaette von Tiahuanako. Mitteilugen der gãographischen Gescllschalft in Wien, vol. 56, 4, 5. Viena, NORDENSKIOLD (Erland)

1917 "Die ostliche Ausbreitung der Tiahuanaco-kuliur in Bolivien und ihr Verhaltnis zur Aresar. kıjitur in rrojos". Zeitschrift für Ethn., 49: 10-20. Berlín,...

1953 Investigaciones arqueo!ógicas en la región fronteriza de Perú y Bolivia. (Trad de su estudio de 1906). La Paz,...

PONCE SANGINES (Carlos)

1948 Cerámica Tiwanakota. Vasos con decoración prosopomorfa. Buenos Aires,..

* 1964 Descripción sumaria del Templete semi-subterráneo de Tiwanaku. Tiwanaku,...

PUCHER ( Leo)

1945 "Los bajorelieves de la pusta del Sol (Tianuanacu). Una nueva interpretación". Univ. San Javier, 13:228-256. Sucre,

POSNANSKY (Arthur)

1911 Tiahuanacu y la civilización prehistórica en el Altiplano Andino. La Paz,.. I10teca de Jetras

1912 Guía general ilustrada para da investigación de los monumentos i-rehistoricos de Tihuanacu é islas del Sol y la Luna (Titica y Koaty) con breves apuntes sobre las Chullpas, Urus y escritura antigua de los aborígenes del Altiplano andino. La Paz,...

1914 Eine Praehistorishe Metropole in Südamerika (Una Metrópoli prehistórica en la América del Sur). Berlín,...

1922 "Breves noticias de una rama cultural Tihuanacu al Noreste cle Bolivia". XX Cong. Int. Am., v. 2, segunda parte, pp. 195 - 197. Río de Janeiro,...

1945 Tihuanacu. The Cradle of American Man (Tihuanacu, cuna del

-57 hombre americano). 4 vs. (en dos tomos). New York y La Paz, RIVA AGÜERO (José de la)

1937 "Raza y lengua probables de la civilización de Tiahuanaco". Opúsculos, 1: 169-202. Lima,...

(*) Véase asterisco anterior. 
ROWE (John H.); COLLIER (Donald); WILLEY (Gordon R.)

1950 "Reconnaissance notes on the site of Huari, near Ayacucho, Perú". Am. Ant. 10: 120-137. Salt Lake City,...

RUBEN (Walter)

1952 Tiahuanaco, Atacama und Araukaner. Leipzig,...

RYDEN (Stig)

1947 Archaeological Researches in the Highlands of Bolivia. Goteborg,... .

1957 Anciean Excavation. I: The Tiahuanaco Era of Lake Titicaca. The Eth. Mus. Sweden. Monog. Series, 4 Stockolm,...

STRONG (William D.)

1957 Paracas, Nazca, and Tiahuanacoid cultural relationships in south coastal Peru. Mem. Soc. Am. Arch., 13. Salt Lake City,...

STUMER (Louis)

1956 "Desarrollo de los estilos tiahuanacoides costeños". Rev. Mus. Nac., 35: 73-88. Lima,...

STŨBEL (A); UHLE (Max)

1892 Die Ruinenstaette von Tiahuanaco im Hochlande des alten Peru. Eiine Kuiturgeschichtliche Stüdio. Leipig,...

TELLO (Julio c.) I blioteca de Ietras

1931 "Las ruinas de Wari" .. El Perú, 27 ago. Lima,...

UHLE (Max)

1903 Pachacamac (University of Pennsylvania). Philadelpha,...

1912a "Los orígenes de los Incas". XVII Cong. Int. Am., 1: 302-354. Buenos Aires,...

1912b "Las relaciones prehistóricas entre el Perú y la Argentina". XVII Cong. Int. Am., 1: 509-540. Buenos Aires,...

1919 "La arqueología de Arica y Tacna". Bol. Soc. Ecuatoriana Est. iHist. Am., v. 3, № 1: 1-48. Quito,...

1934 "Los geroglíficos che la portada de Tiahuanacu". XXV Cong. Int. Am., 2: 199-220. Buenos Aires,...

WALLACE (Dwight T.)

1957 The Tiahuanaco Horizon in the Peruvian and Bolivian Highlands. (Tesis doctoral presentada a la Univ. California, 290 pp.) MS,... 